
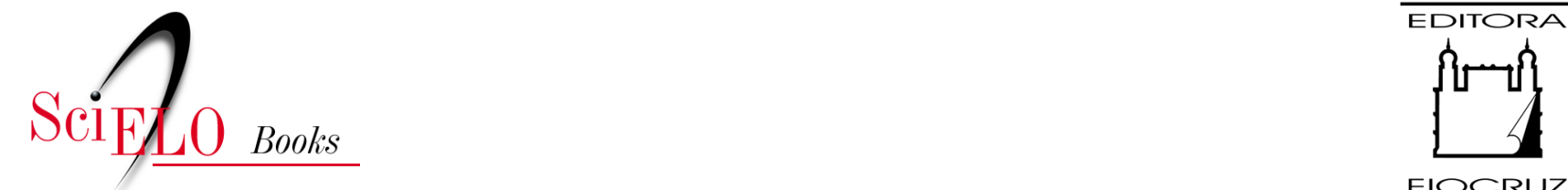

FIOCRUZ

\title{
1. Dos programas de extensão de cobertura aos Programas de Saúde da Família
}

\author{
Joana Azevedo da Silva
}

Ana Sílvia Whitaker Dalmaso

\section{SciELO Books / SciELO Livros / SciELO Libros}

SILVA, J.A., and DALMASO, A.S.W. Dos programas de extensão de cobertura aos Programas de Saúde da Família. In: Agente comunitário de saúde: o ser, o saber, o fazer [online]. Rio de Janeiro: Editora FIOCRUZ, 2002, pp. 19-74. ISBN: 978-85-7541-613-6. Available from: doi: 10.7476/9788575416136.0003. Also available in ePUB from: http://books.scielo.org/id/yw7ns/epub/silva-9788575416136.epub

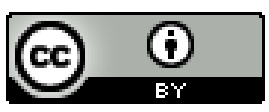

All the contents of this work, except where otherwise noted, is licensed under a Creative Commons Attribution $\underline{4.0 \text { International license. }}$

Todo o conteúdo deste trabalho, exceto quando houver ressalva, é publicado sob a licença Creative Commons Atribição 4.0. 


\section{1 \\ Dos Programas de Extensão de Cobertura aos Programas de Saúde DA FAMÍLIA}

\section{INTRODUÇÃO}

Os Programas de Saúde da Família propostos e implantados tanto em países desenvolvidos como nos em desenvolvimento procuram responder a questões específicas de cada contexto ou se articulam e se sustentam em justificativas orientadas, principalmente, por racionalidades econômicas, científicas e técnicas, associadas a perspectivas 'humanistas', isto é, do bem-estar físico, mental e social, como meta para o ser humano. Correspondem a uma linhagem de propostas com características semelhantes que vêm sendo defendidas, principalmente, a partir da Segunda Guerra Mundial, por organismos ou instituiçóes de natureza pública, nacionais ou internacionais, como modelos para a reorganização da assistência à saúde.

Nessa perspectiva, as últimas décadas têm sido marcadas por repetidas tentativas de organização da assistência à saúde em moldes capazes de conciliar diferentes ordens de determinações que incidem sobre o setor e nele introduzem elementos conflitantes de difícil superação. Destacam-se, entre eles, os que dizem respeito às inovações científicas e tecnológicas experimentadas pela prática médica, com todos os seus corolários - consubstanciados, sobretudo, na questão dos custos crescentes da atenção médica. Dentre essas tendências, ressaltam-se as que refletem as exigências histórico-estruturais da extensão da assistência a parcelas crescentes da população.

Donnangelo, em 1976, já apontava as marcadas modificações por que passava a atenção médica

sob o impacto tanto da nova tecnologia material que, além de modificar inteiramente a prática médica, a articula de maneira peculiar com toda a estrutura de produção de bens materiais, quanto das exigências econômicas e políticas de extensão do consumo de serviços de saúde a categorias sociais até então marginalizadas de tal consumo. (Donnangelo, 1976) 
A autora também identificava a influência dos movimentos de medicina integral, medicina preventiva e, em especial, da medicina comunitária, nas origens dos programas de extensão de cobertura e na utilização de pessoal auxiliar:

Reafirmando os princípios básicos elaborados através de outros projetos de organização da atenção médica, a Medicina Comunitária se propõe operacioná-los através de uma específica estratégia de prestação de serviços à população. Grande parte do campo de ação comunitária em saúde pode ser caracterizado pela busca de extensão da assistência médica a parcelas crescentes da população através do desenvolvimento das atividades de saúde usualmente designadas como de primeira linha. Sua especificidade, entretanto, decorre do fato de que essa extensão da assistência não se fará necessariamente através das modalidades de prestação de serviços e da tecnologia médica predominante, mas, sobretudo, por meio de uma nova estruturação dos elementos que compõem a assistência à saúde, em particular um novo uso do trabalho nesse campo. Reforça-se substancialmente no interior do projeto comunitário um elemento que, embora não seja estranho à prática médica contemporânea, não adquiriu relevância a não ser em raros modelos de organização da assistência. Trata-se do uso do trabalho não médico na área da saúde, articulando-se ao trabalho médico e resultando no que poderia ser designado por trabalhador médico coletivo, atuando de forma tal que, por um processo de distribuição de tarefas, a assistência se efetua através de um conjunto de práticas complementares. (Donnangelo, 1976)

A Conferência Internacional de Cuidados Primários em Saúde, organizada pela Organização Mundial de Saúde (OMS) e pelo Fundo das Nações Unidas para a Infância (Unicef), em setembro de 1978, em Alma-Ata, República do Casaquistão (na época, integrado à União das Repúblicas Socialistas Soviéticas), teve grande repercussão para a implantação, em inúmeros países, de programas de Atenção Primária para populações específicas. No relatório final de AlmaAta, os participantes afirmavam que os cuidados primários de saúde seriam os meios principais para que todas as populações do mundo pudessem alcançar um padrão aceitável de saúde em um futuro próximo. O programa de saúde de uma população precisaria, então, estar integrado ao desenvolvimento social e ter como base o espírito de justiça.

No Brasil, concentram-se, mais precisamente nas três últimas décadas, as tentativas de reorganização da assistência à saúde com esse objetivo específico. Historicamente, a exemplo de outros setores sociais, a saúde ocupou uma posição secundária nas definições de política econômico-social do Estado, bem como no processo de planejamento - em que se abordaram, mais intensamente, os setores econômicos. Os sucessivos planos de desenvolvimento propostos para a sociedade brasileira caracterizaram-se sempre por uma marcada subordinação das medidas na área social aos objetivos específicos da política econômica (Donnangelo, 1976). 
No começo dos anos 70, um marcante contraste caracterizava o cenário da assistência médica brasileira. De um lado, se notava a dominância de uma medicina altamente diferenciada, de custo elevado e intenso consumo por parte de determinado estrato da população; de outro, um elevado número de pessoas que tinham necessidades básicas de saúde sem atendimento.

A remota possibilidade de universalização, na sociedade brasileira, daquele padrão assistencial diferenciado, impunha, por conseqüência, a necessidade do recurso a medidas tendentes a corrigir as distorções do modelo. Parecia óbvia a inviabilidade de medidas que alterassem radicalmente as bases da organização assistencial, daí a busca necessária de formas alternativas de racionalização do conjunto do setor compatíveis com o modelo dominante e capazes, ao mesmo tempo, de tornar o setor menos excludente frente às necessidades de saúde que buscam expressar-se através dele (Donnangelo, 1976).

Concentrando-se, naturalmente, nas definições da política econômica, o II Plano Nacional de Desenvolvimento (1975-1979) (II PND) caracterizava-se, entretanto, pela atribuição de uma relativa autonomia aos setores da área social, cuidando de abordá-los em termos de sua especificidade:

A verdade é que, de um lado, o crescimento pode não resolver o problema da adequada distribuição de renda, se deixado à simples evolução dos fatores do mercado. E, de outro lado, a solução através do crescimento, apenas pode demorar muito mais do que a consciência social admite, em termos de melhorar rapidamente o nível de bem-estar de amplas camadas da população. (II PND, 1975)

Ao mesmo tempo, no plano formulavam-se metas próprias para a política social cuja implicação mais ampla dizia respeito à superação da marginalidade social e cultural - e, naturalmente, econômica. $\mathrm{O}$ aumento da renda real para todas as categorias sociais e a "redução da pobreza absoluta, ou seja, do contingente de famílias com nível de renda abaixo do mínimo admissível quanto à alimentação, saúde, habitação" deviam ser possibilitadas através de uma ação em que se conjugassem medidas mais imediatamente econômicas, como a política de emprego e de salários, com uma estratégia adequada de prestação de serviços sociais (II PND, 1975).

Porém, no referente ao Sistema de Previdência Social,

o decorrer da década de 70 assiste a outras propostas universalizantes que formalmente progrediram no sentido da formulação de um sistema de seguridade social. (...) São exemplos de extensão de cobertura: a instituição da cobertura previdenciária para os maiores de 70 anos $e$ inválidos que tenham, em algum período, contribuído para a Previdência Social ou exercido qualquer atividade a ela vinculada, mesmo sem terem contribuído; a concessão de benefícios aos trabalhadores rurais acidentados no trabalho; a inclusão do salário-maternidade, até então 
sob responsabilidade da empresa; a extensão dos benefícios previdenciários às empregadas domésticas e trabalhadores autônomos, desde que contribuintes do sistema. (Cohn \& Elias, 1996)

Seguiram-se ao II PND uma série de diplomas legais na área social, entre os quais a Lei do Sistema Nacional de Saúde, a primeira definição sistemática, embora limitada, de uma política de saúde para o país.

A Lei no 6.229, de 17 de julho de 1975, dispôs sobre a organização do Sistema Nacional de Saúde. Ocupou-se, basicamente, da designação e da ordenação dos setores institucionais sob cuja responsabilidade deveriam desenvolver-se as ações pertinentes à saúde: o Conselho de Desenvolvimento Social e os ministérios da Saúde, da Previdência e Assistência Social, do Interior, de Educação e Cultura e o do Trabalho. Explicitava as respectivas competências desses setores, dos estados e dos municípios no desenvolvimento das ações, bem como os mecanismos através dos quais se processaria a coordenação, cabendo ao Conselho de Desenvolvimento Social, recentemente criado, assegurar as diretrizes de coordenação geral do Sistema.

Outras conseqüências importantes do II PND foram a proposição e implantação de alguns programas sociais, entre os quais destacam-se, por sua relação com a questão sanitária, o Programa Nacional de Alimentação e Nutrição (Pronan) e o Programa de Interiorização de Ações de Saúde e Saneamento (Piass) (Cordoni, 1979; Rosas, 1981).

A essa época, os Programas de Extensão de Cobertura (PEC) já eram divulgados e defendidos por organismos internacionais e incluídos em documentos, tais como o II Plano Decenal de Saúde para as Américas (1971-1980), resultante da III Reunião Especial de Ministros de Saúde da América Latina. Também a proposta dos PEC já aparecia nas conclusões e recomendações da V Conferência Nacional de Saúde, realizada sob o patrocínio do Ministério da Saúde, em Brasilia, em 1975 (Cordoni, 1979; Rosas, 1981; Brasil, 1975).

A apresentação das políticas de saúde e de suas expressões em programas nacionais ou locais, em ordem de momentos históricos, tem o objetivo de recuperar aspectos considerados nucleares da proposição e da implantação que estejam relacionados à identidade, expectativa de ações e de impacto do trabalho do 'pessoal auxiliar', material central a ser posteriormente resgatado para discutir e traçar o perfil do agente comunitário de saúde, em São Paulo, bem como identificar similaridades ou diferenças em relação a outras propostas que contemplem ou contemplaram esse sujeito como nuclear para sua viabilização.

Tem-se uma perfeita dimensão das limitações a que está exposta essa iniciativa quando se observa que para este resgate se utilizaram fontes e metodologias diversas, sem ignorar as limitações inerentes. 
Apresentam-se, então esses programas, identificando, quando possivel, os seguintes aspectos: contexto histórico em que surgiram, justificativa, objetivos, população-alvo, inserção do agente de saúde e expectativa de impacto de suas ações, mecanismos de seleção, treinamento e supervisão, ações propostas para o agente. A interação do agente com a estrutura organizacional, bem como o espaço de atuação, autonomia de decisão, interação com os outros profissionais, interação com os indivíduos, famílias e comunidade, relacionamento com a estrutura profissional vigente, concepção sobre sua identidade de agente e concepção sobre a importância do seu trabalho para a população também são levados em conta. Considera-se que a identificação destes aspectos possibilitará apreender as dimensões que se tentam retratar neste livro.

\section{Os PROGRAMAS}

Não se podem retomar essas propostas ou suas idéias principais sem se referir primeiro a um serviço pioneiro no Brasil no que se relaciona às idéias e concepções que integram os princípios e diretrizes dos programas aqui analisados: - Serviço Especial de Saúde Pública (Sesp), de 1942 a 1960, e a Fundação Serviço Especial de Saúde Pública (F.Sesp) de 1960 a 1990.

Em 17 de julho de 1942, Osvaldo Aranha, ministro de Estado dos Negócios das Relações Exteriores; Jefferson Caffery, embaixador extraordinário e plenipotenciário dos Estados Unidos e o major George Mundock Saunders, representante do IAIA, assinaram um contrato de cooperação que fazia nascer - Serviço Especial de Saúde Pública, mais conhecido como Sesp. No documento, se instituía uma unidade administrativa mantida pelo IAIA e subordinada diretamente ao Ministério da Educação e Saúde, incluindo entre suas atribuições:

- o saneamento do Vale do Amazonas, especialmente a profilaxia e os estudos de malária no Vale e a assistência médico-sanitária aos trabalhadores ligados ao desenvolvimento econômico dessa região;

- o preparo de profissionais para trabalho de saúde pública, compreendendo o aperfeiçoamento de médicos e engenheiros sanitaristas, a formação de enfermeiras de saúde pública e o treinamento de outros técnicos;

- a colaboração com o Serviço Nacional de Lepra e, por intermédio deste, com as repartições sanitárias estaduais, para o combate à lepra. (Bastos, 1996).

No princípio, todas as atividades do Sesp foram dirigidas, prioritariamente, no sentido de prestar assistência médico-sanitária às populações das áreas onde existiam matérias-primas de interesse estratégico para os países aliados, em guerra contra a Alemanha. Receberam, assim, essa assistência, os trabalhadores removidos do Nordeste para a exploração da borracha na região Amazônica, 
bem como as populações já existentes na área e os que trabalhavam na extração da mica e cristal de rocha nos estados do Espírito Santo, Minas Gerais e Goiás e ainda os que trabalharam na reconstrução da Estrada de Ferro Vitória-Minas, da Companhia do Vale do Rio Doce. Constituía ainda ponto importante do programa médico-sanitário nas regióes o combate à malária. Eram as seguintes, em síntese, as atividades desenvolvidas:

- saúde pública: controle de doenças transmissíveis, estatística vital, enfermagem de saúde pública, educação sanitária, higiene pré-natal e da criança (higiene infantil, higiene pré-escolar, higiene escolar), saneamento do ambiente (água, dejetos, construção de fossas, higiene da habitação, combate à malária, fiscalização de gêneros alimentícios);

- assistência médica: ao adulto, à mulher e à criança;

- laboratório: exames de urina, sangue, fezes, escarro e muco nasal.

De início, as atividades do Sesp caracterizavam-se por monitorar, quase exclusivamente, a situação de saúde dos indivíduos e da família, bem como prevenir e controlar as doenças transmissíveis.

Entretanto, logo nos primeiros anos, a direção do Sesp entendeu que era preciso oferecer também às populações cuidados de assistência médica de que elas necessitavam. Estes serviços, além de constituirem um benefício, tornavamse um atrativo imediato, contribuindo para que as populações aceitassem melhor as medidas preventivas.

A propósito, Bastos (1996) cita o relatório da Conferência da Organização Sanitária, realizada em abril de 1948, da qual participaram técnicos do Sesp, do Ministério da Saúde e da Faculdade de Higiene e Saúde Pública da Universidade de São Paulo. Entre as conclusões da Conferência - que ressaltou a enorme importância do saneamento do meio ambiente, da educação para a saúde, da higiene materna, da higiene da criança, do combate às grandes endemias regionais e da prática de medidas de controle que pudessem ser utilizadas em massa e ao redor dos casos -, destaca-se o que ficou estabelecido em relação à assistência médica:

Considerando que, nas áreas em apreço, as condições de pauperismo das populações e a inexistência ou a insuficiência do número de médicos clínicos e leitos em hospitais forçaram o Programa da Amazônia a instituir serviços de assistência médica, e o do Rio Doce a condescender em prestar esses mesmos serviços no intuito de promover a recuperação, tão rápida quanto possível, da grande massa de doentes ainda existente, a Conferência da Organização Sanitária, reconhece:

a- que se torna necessário, nas áreas de trabalho do Sesp, incluir assistência médica entre as funções de saúde pública. 
b- que a assistência médica, por outro lado, representa um atrativo imediato para a população que, recebendo esse benefício, de melhor maneira se prestará a aceitar as medidas de medicina preventiva.

c- que não será possível prescindir da existência de leitos em hospitais.

Nos anos seguintes, vários foram os atos de prorrogação do contrato que deu origem ao Sesp, até que, em 1960, foi criada a F.Sesp, vinculada ao Ministério da Saúde. A Lei $n^{\circ} 3.750$ definiu os seguintes objetivos básicos para a Fundação:

a- organizar e operar serviços de saúde pública e assistência médicohospitalar nas áreas do território nacional onde se desenvolvem ou venham a se desenvolver programa de valorização, sempre que tais serviços não constem de órgãos federais específicos;

$b$ - estudar, projetar e executar empreendimentos relativos à construção, ampliação ou melhoria de serviços de abastecimento de água e sistemas de esgotos, sempre que não constem de órgãos federais específicos;

c- desenvolver um programa de educação sanitária nas localidades onde mantiver unidades sanitárias;

$d$ - analisar, do ponto de vista técnico, e opinar sobre projetos $e$ orçamentos relativos a serviços de abastecimento de água a serem construídos com financiamento do Banco Nacional de Desenvolvimento ou Caixas Econômicas Federais, nos termos da legislação em vigor;

e- coordenar, organizar e administrar, nos Estados cujos governos o solicitarem, serviços destinados ao desenvolvimento de sua estrutura sanitária básica, inclusive ao que se refere à promoção e controle da higiene industrial;

$f$ - coordenar, organizar e administrar, mediante regime de acordo com as municipalidades interessadas, serviços de abastecimento de água e esgotos;

g- colaborar com os órgãos técnicos do Ministério da Saúde na resolução de problemas de sua competência;

$h$-realizar pesquisas, inquéritos e estudos necessários ao desenvolvimento de suas atividades;

i- promover a difusão de conhecimentos técnicos ligados à saúde pública, através de edição de liuros, revistas e outras publicações;

j- promover a formação e o treinamento de pessoal técnico e auxiliar necessário à execução de suas atividades;

1- desenvolver programas em cooperação com os Estados, o Distrito Federal, os Territórios ou os Municípios, visando a higienização dos bairros pobres e a solução de problemas de saúde pública. (apud Bastos, 1996) 
O resgate a que aqui se procede sobre a F.Sesp baseia-se no entendimento de que a instituição teve uma grande importância na concepção de diretrizes que, atualmente, orientam as práticas de trabalho na proposição dos Programas de Agentes Comunitários de Saúde (Pacs) e do Programa de Saúde da Familia (PSF).

A análise documental não deixa dúvidas que a F.Sesp funcionou como um 'laboratório', foi pioneira na criação de modelos para as propostas de ampliação de cobertura para populações específicas, de práticas, de diretrizes e princípios que, hoje, se colocam, no Pacs e no PSF. Isto permitiu que se construísse experiência e que se avançasse no conhecimento. Entre esses aspectos, destacam-se:

- a oferta organizada de serviços na unidade, no domicílio e na comunidade: a puericultura, o pré-natal;

- o planejamento e a programação; a avaliação realizada em nível central;

- a informação como base para a responsabilização sobre a população da área de abrangência;

- a abordagem integral da família, o prontuário familiar;

- a unidade de saúde dinâmica, não estática; a unidade de saúde indo à população e vice-versa;

- a adscrição de clientela;

- o trabalho com a comunidade;

- o monitoramento do trabalho e o treinamento de parteiras leigas, as "curiosas";

- a incorporação das atividades de assistência médica ao trabalho das unidades de saúde;

- a incorporação de pessoal auxiliar no atendimento aos grupos prioritários (gestante e crianças) e no controle de doenças transmissíveis;

- a visita domiciliar, realizada por visitador sanitário e auxiliar de saneamento, para atividades de promoção da saúde, prevenção de doenças, monitoramento de grupos de risco e vigilância sanitária;

- o tratamento supervisionado para o controle de doenças prevalentes, como a tuberculose;

- a organização de sistema de saúde regionalizado e hierarquizado: postos de saúde, unidades sanitárias, unidades mistas e hospitais;

- o enfoque intersetorial: a incorporação das atividades de saneamento básico ao trabalho das unidades, através da atuação do inspetor de saneamento e do engenheiro; a educação sanitária como mola mestra das ações; 
- a capacitação, em serviço, de profissionais e a preparação de pessoal de nível médio: laboratorista, auxiliar hospitalar, visitadora sanitária, guarda sanitário, auxiliar de saneamento, higienista dentária, ecônoma;

- a educação continuada para os profissionais;

- a educação para a Saúde;

- a integração docente-assistencial;

- o apoio às escolas de nível superior, em especial, as de enfermagem, em quase todo o Brasil, para garantir formação dos profissionais necessários às ações de saúde.

$\mathrm{Na}$ F.Sesp, as visitadoras sanitárias - auxiliares que desenvolviam o atendimento aos indivíduos e às famílias, na unidade e na comunidade, sob supervisão e orientação do enfermeiro, e mediante protocolos estabelecidos - eram responsáveis por atender a gestantes e crianças de baixo risco, na 'unidade sanitária'.

O primeiro atendimento da gestante era sempre um atendimento de enfermagem, ocasião em que a visitadora avaliava as condições de desenvolvimento da gravidez, solicitava os exames definidos em protocolo, agendava esses exames, realizava pesquisa de albumina na urina e agendava o retorno com o médico para quando os exames estivessem prontos. As visitadoras ainda se encarregaram de fazer as visitas domiciliares a puérperas e recém-nascidos; acompanhar nascidos-vivos e óbitos menores de um ano $e$ monitorar pacientes portadores de doenças prevalentes.

Cada uma das visitadoras sanitárias era, também, responsável pela cobertura da população residente em uma determinada área do município. $\mathrm{O}$ treinamento para o trabalho, com duração de seis meses, era realizado por um enfermeiro, logo após a admissão, mediante programa validado e publicado pela instituição, no qual uma metodologia de integração ensino-serviço favorecia o desenvolvimento dás competências necessárias à prática das funções.

Em 1990, a F.Sesp foi incorporada à Superintendência de Campanhas de Saúde Pública (Sucam) quando da criação da Fundação Nacional de Saúde (FNS), vinculada ao Ministério da Saúde.

O orgulho de toda uma geração de 'sespianos' é, provavelmente, devido ao fato de pertencer a uma escola pioneira em métodos e técnicas apropriados e que muito contribuiu para o aprendizado e para a saúde do povo brasileiro. Posteriormente, muitos deles assumiram posições de destaque na proposição e implantação de modelos que visavam à extensão de cobertura e à reorientação do modelo de assistência à saúde no Brasil. Segundo Bastos (1996), a F.Sesp possibilitou a emergência de uma nova consciência em saúde pública no país e de vigorosas lideranças. 
Entende-se, assim, porque qualquer trabalho que se proponha a estudar os modelos de reorientação da assistência à saúde no Brasil, necessariamente terá de passar pela história do Sesp e da F.Sesp.

\section{O PIASS, PRIMEIRA ETAPA, NORDESTE - 1976-1979}

O Programa de Interiorização de Ações de Saúde e Saneamento (Piass) foi, entre os Programas de Extensão de Cobertura, aquele que, institucionalizado como política governamental, conseguiu maior expressão. Além de absorver outros programas importantes, como o Programa de Integração de Serviços de Saúde do Norte de Minas, recobriu, em um primeiro momento, o Nordeste, e acabou tornando-se objeto de uma proposta de expansão a outras áreas rurais do território nacional. O Programa foi instituído, para a região Nordeste do País, pelo Decreto Presidencial de 24 de agosto de 1976, para o período 1976/1979. A finalidade era implantar uma estrutura básica de saúde pública nas comunidades de até 20 mil habitantes, bem como contribuir para a melhoria do nível de saúde da população local (Rosas, 1981).

O Piass propunha-se a adotar uma ampla gama de práticas que se estendiam desde as questões relacionadas ao meio ambiente até os problemas sanitários que demandavam atenção médica individual. As diretrizes básicas do Piass estavam expressas no artigo $2^{\circ}$ do Decreto:

I - ampla utilização de pessoal de nível auxiliar, recrutado nas próprias comunidades a serem beneficiadas;

II - ênfase na prevenção de doenças transmissiveis, inclusive as de caráter endêmico, no atendimento de nosologias mais freqüentes e na detecção dos casos mais complexos, com vistas ao seu encaminhamento a serviços especializados;

III - desenvolvimento de ações de saúde caracterizadas por serem de baixo custo e alta eficácia;

IV - disseminação de unidades tipo miniposto, integradas ao sistema de saúde da Região e apoiadas por unidades de maior porte, localizadas em núcleos populacionais estratégicos;

$V$ - integração no nivel dos diversos organismos públicos integrantes do Sistema Nacional de Saúde;

VI - ampla participação comunitária;

VII - desativação gradual de unidades itinerantes de saúde, a serem substituídas por serviços básicos de caráter permanente. (Brasil, 1976, apud Rosas, 1981)

A participação comunitária aparecia, no texto, a um só tempo, como necessária e limitada. Derivava do caráter permanente e simplificado da estrutura a ser estabelecida em cada nível de atenção, para cuja sustentação a comunidade devia estar mobilizada. Essa mobilização orientava-se no sentido de garantir o 
apoio ao programa e à execução, pela população local, de atividades necessárias à manutenção controlada dos custos e à própria operacionalização das ações previstas. Era o caso, por exemplo, da participação proposta para: implantação de sistemas simplificados de abastecimento de água, de destino de dejetos e do lixo; suprimento mínimo de alimentos através do incentivo à formação de hortas e de pomares e à criação de animais de pequeno porte; custeio parcial, em âmbito local, das atividades em desenvolvimento. Para tal mobilização, encontrava-se previsto o treinamento de pessoal auxiliar, no interior da própria estrutura de serviços.

Todas essas proposições básicas parecem ter se tornado passíveis de algum grau de recomposição, em nível local, na dependência das características dos grupos envolvidos e dos processos ocorridos em nível central (Donnangelo, 1976). Evidentemente, esse processo, essas inflexões de diretrizes não se processaram sem marcados confrontos de tendências, tanto em nível central, como regional ou local. Deve-se entender o processo de desenvolvimento do Piass como um processo político que reproduziu, em nível local, questões políticas sempre presentes na sociedade brasileira, como um todo e, em especial, nas localidades onde se implantaram.

Outros projetos e atividades também se estruturaram com vistas a proporcionar os necessários suportes para o desenvolvimento dessa nova política de atuação na área da saúde. Tal foi o caso do Programa de Preparação Estratégica de Pessoal de Saúde (PPREPS), destinado a

adequar progressivamente a formação de recursos humanos para a saúde aos requerimentos de um sistema de serviços com máxima cobertura possível e integral, regionalizado e de assistência progressiva, de acordo com as necessidades das populações respectivas e as possibilidades das diversas realidades que o país apresenta. (Donnangelo, 1976)

Criado em 1975, através de um acordo de cooperação técnica entre o Ministério da Saúde e a Organização Panamericana de Saúde, o PPREPS visava à preparação de recursos humanos adequados a um processo de extensão de cobertura subordinado às necessidades e possibilidades de diferentes áreas do país. Propunha, para tanto, a preparação, em larga escala, de pessoal de saúde de nível médio e elementar (Donnangelo, 1976).

A 14 de novembro de 1979, foi aprovada, através de Decreto Presidencial, a expansão nacional do Piass para o período 1980-1985. A estratégia definida pela coordenação nacional do Piass incluía, como diretrizes básicas, a operação e manutenção da rede básica já instalada; a ampliação da rede, a fim de cobrir a totalidade dos municípios da área de abrangência do Programa, com vistas à sua consolidação; o fortalecimento e reestruturação das secretarias estaduais de Saúde; a busca da extensão do Programa para o âmbito nacional, para regiões 
com características populacionais e de serviços semelhantes às primeiras localidades em que o programa havia sido instalado (Brasil, 1979).

\section{O PIASS, SEGUNDA ETAPA, EXPANSÃO NACIONAL - 1980-1985}

\section{O Piass, no Vale do Rio Ribeira, em São Paulo - Projeto Devale}

Após negociações da Secretaria de Estado da Saúde (SES) com o Ministério da Saúde, incluiu-se o estado de São Paulo - representado pelas regióes de Sorocaba e Vale do Ribeira - na área de abrangência da expansão nacional do Piass. Como decorrência, inicia-se, em 1981, o Projeto de Expansão de Serviços Básicos de Saúde e Saneamento em área rural, Vale do Ribeira, que contaria com recursos do Estado, do Ministério da Saúde e do ex-Inamps (Silva et al., 1986; São Paulo, 1981).

O Projeto Devale, como ficou conhecido, contava com a participação de agentes de saúde em postos de saúde rurais e na comunidade, de 17 localidades rurais de 8 dos 16 municípios da região (Silva, 1983).

De 1967 a 1970, o Estado de São Paulo, assistiu, na gestão de Walter Leser, na Secretaria da Saúde, no processo da Reforma Administrativa, a um movimento de valorização da atenção básica, a uma política de programação da oferta de serviços de saúde.

Se essa política não previa a figura do agente ou do auxiliar de saúde, incorporou, inspirada na F.Sesp, a do visitador sanitário, com algumas atribuições similares.

Os desdobramentos desta política, as idas e vindas da identidade desse sujeito que não chegou a se definir não serão objeto de discussão, no recorte privilegiado para este trabalho.

Em São Paulo, cabe também lembrar, na perspectiva de política de uso de pessoal auxiliar, do movimento dos Centros de Saúde-Escola, com o objetivo de desenvolver, nos alunos de graduação da saúde, a capacidade de atuar na atenção básica, com oferta organizada de serviços à população e participação de pessoal auxiliar na realização de várias das dimensões almejadas (Cyrino, 1993).

Em meados da década de 70, a partir da eleição direta para prefeito em cidades que não eram capitais de estados ou consideradas municípios estratégicos, multiplicaram-se, pelo país, iniciativas municipais para resolver demandas sociais emergentes e urgentes. Uma das áreas de escolha, pelos novos dirigentes, foi a da saúde. Vários municípios implantaram programas dentro dos princípios da Atenção Primária à Saúde. Os programas de agentes de saúde foram uma 
destas vertentes. Para concretizá-los, os responsáveis tiveram de unir empenho e criatividade, já que muitas vezes não dispunham do conhecimento necessário, nem de orientação oficial. São José dos Campos (SP) é um dos municípios que dispõem dessa experiência desde 1979.

A partir de Silva (1984) e Silva et al. (1986), busca-se recuperar, aqui, a experiência do Piass do Vale do Ribeira (Projeto Devale). Os pesquisadores avaliaram, entre 1983 e 1984, a implantação do projeto, bem como o trabalho dos agentes de saúde, atividades financiadas por um convênio entre o Ministério da Saúde e a Universidade de Campinas (Unicamp). A caracterização do programa poderá vir a ser mais completa do que os demais estudos em virtude de implicar vivência pessoal de uma das autoras deste livro com os fatos e os aspectos relatados. Em relação ao contexto histórico de emergência e às justificativas, o depoimento a seguir é bastante significativo:

Eu estava em Juquiá, há quase quatro anos, fazendo todo um trabalho de morrer, de atender doentes. Atendendo doentes de manhã até a noite, e isso ... Nós fomos vendo que resolvia muito pouco. Nós atendíamos as pessoas que ficavam mais próximas ao centro de saúde. As pessoas que não tinham acesso, tinham dificuldades enormes. $\mathrm{Na}$ hora em que chegavam ao centro de saúde, já não havia ficha. Nós fomos nos cansando deste tipo de atendimento, apesar de discutirmos outros tipos de atividades, de discussão da problemática de saúde, das condições de vida ... Apesar dessa agonia, estávamos sempre atendendo às mesmas pessoas. (Técnico da coordenação do Projeto Devale)

Inclusive uma coisa marcou muito. $\mathrm{O}$ que aconteceu com uma familia de desnutridos, porque a mãe, ela era de Barra do..., são mais de 32 quilômetros para chegar até aqui. As crianças estavam bastante desnutridas, demos o leite e explicamos que ela devia pegar o leite por mais tempo e a mãe falou assim: "Olha, a senhora não precisa me dar mais leite porque eu não tenho condições de chegar até aqui". Até para coisas tipo desidratação (...) essas pessoas estavam sendo deslocadas. Eu tive um caso de uma criança que morreu por acidose, porque ela estava tão desidratada que o corpinho dela não resistiu e ela acabou falecendo; e foi por causa da distância. A mãe veio a pé, debaixo do sol, lá de Barra do... para cá e não deu tempo de a criança chegar aqui. Chegou já mortinha. E isso aí eu acho que devia ser freqüente, não só aqui, em todos lugares. (Técnico da equipe de coordenação do Projeto Devale)

A equipe realizou um levantamento das condições de saúde na região do Vale do Ribeira, bem como do equipamento disponível. O documento funcionou como ponto de partida para um relatório, em que se apresentavam conclusões e sugestões. A ênfase maior recaía na garantia de acesso, na integração de recursos, no funcionamento das unidades e no atendimento à população da zona rural. 
A essa mesma época, a SES apresentava ao Ministério da Saúde o Plano Operativo Anual (POA), para que as duas instâncias de governo pudessem iniciar um convênio. As diretrizes do Ministério da Saúde para 1981 - que incluíam a ênfase na operação da rede de serviços básicos de saúde, a participação comunitária, a regionalização, a integração programática, a integralização de ações de saúde e o desenvolvimento de recursos humanos e de tecnologia simplificada e apropriada - fizeram com que esse plano de trabalho para o Vale do Ribeira fosse incluído no Plano Operativo daquele ano como um projeto prioritário.

Foi então elaborado o Projeto de Expansão dos Serviços Básicos de Saúde e Saneamento em Área Rural - Vale do Ribeira (Projeto Devale) que, aprovado em nível federal, dava início à implantação do Piass no estado de São Paulo, em 1981.

Ao se estudar detalhadamente o material disponivel, os objetivos, as estratégias, o desenvolvimento do Projeto, as entrevistas realizadas, percebe-se a grande preocupação da equipe de coordenação do Devale com determinados aspectos:

- a extensão de atividades de assistência primária à população residente na periferia dos centros urbanos e na zona rural, mediante a instalação de postos de saúde operados por agentes de saúde recrutados na própria comunidade: "levar para mais perto de onde as pessoas moram, trabalham, uma série de atividades ligadas à atenção primária que eram, até a época de implantação do Projeto, somente realizadas no centro de saúde do município".

- a preparação da rede existente para servir de retaguarda à demanda gerada pelos postos de saúde;

- a coordenação das instituições de saúde existentes na área e o funcionamento integrado dos serviços;

- a integração entre as atividades de saúde e saneamento a serem desenvolvidas;

- a definição do sentido e dos limites das atividades do agente de saúde (esse aspecto aparece nas entrevistas com os técnicos integrantes da equipe de coordenação como de fundamental importância no desenvolvimento do Projeto);

- a viabilização de um espaço para discussão e organização da comunidade, em relação à problemática relacionada com a saúde:

Você tem, de alĝuma forma, de levar a discussão para essas comunidades, tentar fazer com que as pessoas comecem a se juntar para discutir os problemas de saúde: por que eles existem; a causa desses problemas; por que [alguém] toma remédio; melhora e depois fica doente de novo; os condicionantes... E, com isso, estimular que eles vão procurando 
alternativas de resolver esses problemas do mais fácil para o mais difícil, do mais imediato ao mais mediato, sei lá, como eles achem que deveriam fazer. Mas eu acho que isso aí é tão importante quanto... não é o caso de comparar, mas eu acho que uma coisa é a própria discussão de ter um posto aqui, por que é importante, sabe? Começando por aí, por uma coisa concreta que é a possibilidade de você ter um agente de saúde treinado no bairro $e$ as possibilidades de você ter um local para as pessoas não só virem procurar atendimento ou orientação, mas também para conversar, trocar idéias, e com isso irem crescendo, organizandose em função dos seus problemas de saúde, ou em função de outros problemas que eles achariam que têm ou não a ver com a saúde. Porque se a gente só pensar nesse objetivo de expansão de ações, de ação primária, desvinculando dessa outra problemática, dessa discussão, dessa experiência, dessa participação que tende a uma organização.

(Diretor de Unidade de Saúde)

Embora não se tenha evidenciado uma preocupação em definir previamente as atividades a serem desenvolvidas pelo agente de saúde, em cada localidade rural, foi possível identificar três componentes principais que deveriam integrar o conjunto da prática do agente de saúde:

- um componente mais estritamente técnico, relacionado ao desenvolvimento de atividade de atenção individual, de atendimento a queixas ou problemas;

- um componente relacionado às atividades comunitárias;

- um componente relativo ao modo como deveria ser desenvolvido esse conjunto de atividades indicadas nos itens anteriores.

Diferentes motivos - entre os quais a heterogeneidade dos locais onde o agente iria atuar, a localização do bairro em termos de acesso a serviços médicos e a proposta de que o agente de saúde e a população da localidade participassem dessa definição - fizeram com que o componente de conteúdo mais estritamente técnico ficasse para ser determinado no treinamento dos agentes de saúde, ocasião em que seriam mais adequadamente consideradas as expectativas da população e do próprio agente, em relação ao trabalho a ser executado. Nesta perspectiva, detectou-se uma clara preocupação, por parte dos responsáveis pela operacionalização do Projeto, de não hipertrofiar a função considerada mais técnica, no atendimento individual, em detrimento das atividades coletivas, mesmo assumindo a necessidade daquele atendimento à demanda do cliente, devendo o seu caráter de prioridade ser definido na situação concreta.

A esse respeito, transcrevem-se, a seguir, trechos de entrevistas com técnicos da equipe de coordenação e diretores técnicos de centros de saúde da região.

Quando a fome é muito grande e está apertando muito, a primeira necessidade é resolver aquela fome urgente daquele momento; então ela [a população] faz opção por aquelas pessoas que têm condições de 
resolver aquela fome urgente. Acho que, no postinho, o negócio é também por aí; quando você tem uma necessidade, um volume grande de atendimentos, de consultas... o agente não abriu o postinho porque vai fazer reunião, não. Se a pessoa está com as crianças com diarréia, com não sei mais o quê, ela vai querer primeiro tratar a diarréia. Se o agente não está tendo tempo, ter um segundo agente, ter um terceiro agente naquele bairro. Então eu acho que não deve ser só essa função curativa, que é a reivindicação da população, é um direito dela. Mas nós devemos dar condições de trabalho para que o agente faça os dois papéis; coloca-se mais um agente para que ele possa desenvolver outras atividades.(Técnico da coordenação do projeto)

Eu acharia fundamental se a gente conseguisse desenvolver essa discussão sobre a problemática de saúde. Isso eu acho a 'pedra de toque' do negócio. Agora, a gente vê que não é essa a expectativa do bairro. $\mathrm{O}$ bairro tem uma expectativa muito mais que seja uma pessoa que resolva os problemas de saúde, ou melhor, resolva os problemas de doenças. Eu acho que aí cabe à gente tentar fazer uma média das duas coisas. Tentar fazer com que o agente tenha condições de desenvolver aquelas atividades que o bairro considera que são atividades de atenção à saúde importantes, como por exemplo, picada de cobra, e além disso, essa atividade, que é mais que uma atividade, seria assim uma postura do agente de saúde frente aos problemas de saúde lá do seu bairro, discussão desses problemas, de tentar, juntamente com o bairro, encontrar as formas de encaminhar a solução desses problemas e essa outra parte, importante também, que é a reivindicação, a expectativa que o bairro tem do agente, que é a atenção aos problemas de saúde e aos problemas de doenças (...) Então há essas atividades como vacinação, primeiros-socorros em caso de corte, queimaduras, em caso de traumatismos por pancada, uma imobilização simples, acompanhar o desenvolvimento de crianças no primeiro ano de vida, acompanhar uma gestação, são coisas que, pela freqüência com que elas acontecem e pela importância que elas têm, acho que dá até para achar que são atividades importantes em todos os treinamentos, mas a maioria das coisas deve sair mesmo durante o treinamento. Agora, essa atividade que eu acho importantíssima, que o agente estimule, que no bairro ocorra a discussão de problemática de saúde, que é inclusive a organização do bairro, que acaba envolvendo a organização em função de sua própria vida ... essa não é uma coisa que as pessoas do bairro esperam que o agente saiba fazer. Mas eu acho que a partir do próprio treinamento, quando o próprio agente começa a se interessar por essa discussão, sentindo a sua importância, ele consegue levar isso para o bairro. (Técnico da coordenação do projeto)

É que eles, em primeiro lugar, consigam levantar uma discussão sobre saúde no bairro. (...) Sobre os condicionamentos de saúde, por que as pessoas têm ou não têm saúde, por que aparecem tais ou quais doenças, quais as doenças mais importantes... Depois, exercer um papel de 
educação (...) partindo do que a própria comunidade vai conhecendo, vai colocando (...) de descobrir um conhecimento junto (...) de descobrir as maneiras de ter saúde (...) de passar conhecimentos adquiridos. Também atender às pessoas, talvez tenha sido essa a idéia inicial (...) por causa de falta de acesso das pessoas. (...) Não há ônibus ou qualquer meio de transporte; quando há, a passagem é caríssima ... As ações de saúde estariam mais acessíveis às pessoas de zona rural. Então vacinação, suplementação alimentar e mesmo atendimento a doenças assim mais simples, que eles mesmos possam tratar ou com remédio que o postinho recebe ou com a própria medicina caseira que eles conhecem, chás... Não assumir o papel de instituição... Saber sempre o que estão fazendo e por que... Não ver só a doença ou um pedaço do corpo... ver a pessoa como um todo. (Técnico da coordenação do projeto)

Sintetizando, a proposta de ação para o agente de saúde, no Projeto Devale incluía:

- proporcionar a extensão do atendimento aos problemas de saúde da população rural por meio da aplicação de conhecimentos e execução de atividades específicas (curativos, vacinas, diagnósticos e tratamento de doenças mais prevalentes, atendimento à criança e à gestante, encaminhamentos, primeiros socorros);

- adotar uma visão global do indivíduo e seu papel na comunidade;

- incorporar um componente de discussão desses problemas de saúde em função das condições gerais de vida da população;

- organizar a comunidade para lutar pela saúde.

A escolha das localidades rurais onde seriam instalados os postos de saúde foi efetuada pela equipe de coordenação do programa, com os médicos dos centros de saúde, professores comunitários e prefeitos, tomando como referência o levantamento realizado nos municípios. Em uma primeira fase, definiu-se a implantação em dezessete localidades rurais pertencentes a oito municípios da região. Estes municípios foram escolhidos porque já dispunham de médicos sanitaristas nos centros de saúde, o que propiciaria uma maior facilidade para o desenvolvimento da supervisão aos postos. Além disso, pelo fato de já terem participado das discussões quando da proposição do projeto, teriam mais condições de modificar a estrutura dos centros de saúde, adaptandoos para servirem de referência aos clientes encaminhados pelos postos.

A partir das prioridades estabelecidas para a implantação das unidades de saúde, contactaram-se os professores comunitários, os representantes da Igreja e outros líderes. O objetivo era realizar reunião dos moradores dos bairros indicados para discutir o posto de saúde e a escolha do agente de saúde. Quase sempre durante as reuniões era constituída uma comissão - integrada pelo futuro agente de saúde, bem como por outros moradores presentes -, encarregada de tomar as providências relativas ao prédio. 
Quanto ao processo de escolha dos agentes de saúde, de início, os moradores demoravam a acreditar que lhes caberia realmente a indicação da forma de escolha e a própria escolha do agente de saúde. Essa atitude pode estar relacionada à época em que vivíamos -1981 - ainda sob o regime militar, sem eleições diretas. Colocações, como as que se seguem, eram comuns em reuniões: "melhor seria que vocês mesmos escolhessem"; "vocês são médicos, enfermeiros, vocês é que sabem". Após a reação inicial de incredulidade, seguiamse afirmações do tipo: "É bom mesmo a gente escolher, porque quem põe tira!"

Dando início à escolha propriamente dita, o coordenador da reunião perguntava aos presentes sobre a opinião predominante a respeito de como deveria ser a pessoa que iria trabalhar no postinho. Essa colocação era sempre seguida de uma listagem, elaborada pelos presentes, das qualidades que a pessoa deveria ter e quais os defeitos que não poderiam ser admitidos. Estavam, assim, sendo definidos os critérios para a seleção do futuro agente de saúde. A relação das qualidades necessárias ao agente, elaborada pelos moradores dos diferentes bairros, exprimiu, de certa forma, a expectativa geral frente ao trabalho a desenvolver.

Alguns desses critérios foram lembrados em praticamente todas as reuniões, como por exemplo:

- "não fazer distinção entre as pessoas, tratar todo mundo igual pobre e rico, preto e branco, parente ou não parente, da mesma religião ou de outra";

- "saber ler e escrever" - este critério gerou ampla discussão entre os participantes: "Quanto mais estudo tiver, melhor"; "Se a gente for exigir muito estudo, no bairro não tem ninguém com muito estudo". Ao final, decidiram optar pelo nível de escolaridade oferecido pelo bairro;

- "ter jeito para a coisa";

- "não ter medo de sangue";

- "não ter medo de dar injeção";

- "ser responsável";

- "não ter orgulho";

- "ser maior de idade" - a indicação desse último critério variou muito nas diferentes reuniões. Após as discussões, ficava acertado que o agente de saúde deveria ser maior de idade, mas não idoso;

Em algumaslocalidades, outras qualidades foram julgadas necessárias:

- "comprometimento com a comunidade";

- "ter boa vontade";

- "ter tempo"; 
- "ser educado, calmo, atencioso";

- "ser decidido";

- "não beber";

- "andar ligeiro" - a inclusão desse critério refletia as precárias condições de transporte do Vale, prevendo que, na maior parte das ocasiões, os agentes teriam de se locomover a pé.

A necessidade de o agente ser do bairro não foi manifestada, provavelmente, por estar implícita.

Depois de definirem as qualidades que deveria ter o agente de saúde, os moradores sugeriam nomes para a votação. Na maioria das localidades, após a indicação dos nomes, era procedida uma eleição, pelo sistema de votação secreta. Esse sistema foi igualmente escolhido pelos presentes, após muitas discussões: "Votação secreta é melhor, porque assim a gente fica mais à vontade, ninguém fica sabendo, nem fica chateado, cada um vota só com a sua cabeça e não vai votar porque o outro é primo, amigo ou parente".

Os votos eram, na maioria das vezes, colocados em urnas improvisadas, como chapéus de participantes. A apuração era sempre feita no local, com os eleitores servindo de fiscais de votação e de apuração.

Embora, em todas as reuniões dos bairros, os moradores tivessem expressado claramente a opinião de que o agente de saúde poderia ser homem ou mulher, entre os escolhidos verificou-se absoluta maioria do sexo feminino (quinze mulheres e quatro homens), apesar de terem concorrido candidatos de ambos os sexos, em todas as eleições.

O grau de instrução foi um dos temas mais debatidos nas reuniões, tendo ficado como opinião mais aceita a de que essa característica não tinha tanta importância, pois, nos bairros rurais, não havia "pessoas muito instruídas". É interessante notar, entretanto, que a escolha recaiu, na maior parte das vezes, em pessoas que tinham um nível de escolaridade superior ao da média da população.

Outra característica geral dos agentes de saúde, relatada a partir das entrevistas, é a de terem sido escolhidas pessoas que já desempenhavam uma função similar à esperada para o agente. Em alguns casos, essas funções eram até relacionadas à saúde: pessoas que eram habitualmente procuradas para dar orientações referentes a problemas de saúde ou para prestar serviços como aplicação de injeções, realização de curativos etc. Na maioria dos casos, porém, as pessoas selecionadas já desenvolviam algum tipo de atividade comunitária, como as realizadas na igreja (clubes de mães e de jovens), pelas escolas comunitárias ou as decorrentes de associações civis voluntárias e informais, relacionadas à discussão de problemas comuns. 
Os coordenadores também viviam um momento de decisões, já que atuariam como instrutores e deviam respeitar as características de cada região ao iniciar o projeto. Algumas preocupações se faziam evidentes:

- o treinamento teria de atender à proposta de atividade a ser desenvolvida pelo agente de saúde, ou seja, deveria possibilitar aos treinandos o instrumental necessário (conhecimentos, técnicas de metodologia de trabalho) à realização das diversas dimensões do trabalho a fazer na comunidade. Deste modo, o treinamento deveria abranger não apenas a aquisição de conhecimentos, mas também o desenvolvimento da capacidade crítica de análise, a motivação para pensar junto com o bairro, caminhar junto, discutir e tentar resolver os problemas em conjunto. Para que este objetivo múltiplo fosse alcançado, no desenvolver do trabalho de cada um, era necessário percebê-lo e exercitá-lo durante o treinamento;

- o conteúdo do treinamento deveria respeitar fundamentalmente os aspectos que o agente de saúde trouxesse como reivindicações, como expectativas do bairro em relação à sua atuação. Na medida do possível, o agente deveria ser capacitado a atender a essa demanda;

- como conseqüência, os conhecimentos e técnicas que os agentes deviam apreender seriam definidos durante o treinamento. Essa preocupação não incluía, entretanto, a renúncia por parte dos técnicos à habilitação dos agentes para o trabalho com os problemas de saúde mais prevalentes na região, ou para a execução das atividades previstas nos programas e subprogramas da SES/SP;

- a metodologia a adotar deveria garantir uma participação ativa dos treinandos, no sentido de proporcionar uma troca de conhecimentos, experiências e modos de ver e pensar entre alunos e instrutores;

- o processo de capacitação dos agentes não deveria afastá-los do bairro mas, pelo contrário, procurar mantê-los como elementos do grupo social a que sempre pertenceram;

- o treinamento inicial, previsto para dois meses, não seria suficiente para a capacitação do agente; etapas posteriores de continuidade do processo deveriam, portanto, ser asseguradas.

O modelo de treinamento sugerido visava a atingir duas preocupações básicas: fortalecer o compromisso e a solidariedade do agente de saúde com a comunidade e prover condições para que ele/ela dispusesse do instrumental adequado e necessário para lidar com os problemas de saúde do grupo.

A metodologia proposta, na tentativa de privilegiar o como manter ou aumentar o compromisso do agente de saúde com a população, durante a 
capacitação, visava a proporcionar o desenvolvimento de competências para conhecer criticamente as situações de saúde no contexto da realidade em que elas apareciam e buscar um saber que correspondesse à necessidade de mudar tais situações.

Em termos metodológicos, no sentido de promover o desenvolvimento do processo ensino/aprendizagem, a proposta em discussão traduzia-se no recurso a uma série gradual e encadeada de situações. Este recurso visava a proporcionar condições de integração entre o que os treinandos traziam como experiência anterior de vida e os conhecimentos que lhes seriam transmitidos durante o treinamento. Da mesma förma, os conteúdos deveriam ser construídos a partir dos saberes dos alunos, o que facilitaria o salto quantitativo dos conhecimentos e comportamentos já existentes para os comportamentos e habilidades necessários ao trabalho.

Com base nessas considerações, o treinamento dos agentes de saúde do Vale do Ribeira constituir-se-ia na etapa inicial do processo de ensino/ aprendizagem. Este processo deveria seguir, com a prática, nas localidades rurais.

Finalmente, os instrutores consideravam que, para o encaminhamento das questões centrais relativas ao processo de aprendizagem - quais as formas de conhecer e pensar das pessoas a serem capacitadas e qual a estrutura do conhecimento que deveria ser assimilado - teriam de conduzir o treinamento tendo em mente alguns princípios fundamentais:

- procurar ver saúde no contexto geral de vida;

- identificar as formas de conhecer e de pensar das pessoas;

- partir do conhecimento que os indivíduos têm do problema;

- compreender a importância do diálogo na comunicação e no processo ensino/aprendizagem;

- procurar aprender com os demais;

- devolver, sempre, ao interessado o resultado de qualquer estudo;

- reforçar o grupo no encaminhamento dos problemas;

- refletir, continuamente, sobre o trabalho realizado.

O treinamento dos agentes de saúde do Vale do Ribeira durou doze semanas, dez na sede do treinamento e nas localidades rurais e duas de estágio prático, nos centros de saúde de cada município. Na primeira semana de treinamento, as atividades foram: apresentação pelos alunos dos problemas de saúde dos seus bairros, discussão sobre a situação dos prédios onde iriam funcionar os postos, em cada localidade e apresentação da história de cada bairro.

Na seqüência, em termos de grupo, a necessidade que se colocava era: como fazer para conhecer os problemas do dia-a-dia do bairro? Como ficar 
sabendo o conhecimento que as pessoas têm dos problemas? À medida que surgiam as idéias, eram debatidas. Ao final, se montou uma espécie de roteiro, que expressava, de forma geral, o modo como o agente de saúde deveria trabalhar na comunidade e o tipo de trabalho a desenvolver:

- ter boa comunicaçãocom os moradores;

- partir do conhecimento das pessoas do bairro e não dos próprios conhecimentos;

- aprender uns com os outros;

- devolver as perguntas aos moradores. Não tentar dar respostas prontas;

- dar tempo para as pessoas pensarem;

- juntar o maior número possível de habitantes quando discutir um problema;

- não se afastar dos moradores;

- partir dos problemas do dia-a-dia do bairro;

- conhecer melhor os problemas do bairro, por meio de: a) visitas às casas; b) reuniões; c) pesquisas (procurar fazer este trabalho em grupo); d) conversas descontraída, sem perguntas prontas; e) não deixar que as anotações atrapalhem a conversa;

- devolver ao bairro os resultados dos levantamentos dos problemas;

- tentar resolver os problemas juntamente com a comunidade;

- escolher, em conjunto com as pessoas do bairro, o que fazer em cada momento.

Os treinandos passaram, então, toda a semana seguinte nos bairros, desenvolvendo o estudo. Após o retorno, cada aluno relatou sua experiência.

O objetivo do levantamento realizado, além de conhecer os efetivos problemas de saúde que os moradores identificavam, era colher informações referentes às causas desses problemas e ao modo como tentavam resolvê-los. No levantamento de dados, utilizaram-se as informações obtidas nas visitas e nas reuniões. Os temas se entrelaçavam, de maneira que o que se falava nas casas em que esteve o agente de saúde podia ser o assunto do encontro seguinte. $\mathrm{Na}$ hora da reunião, os moradores discutiam amplamente os problemas, o modo de encará-los e as possíveis soluções. Um tema bastante solicitado era o conteúdo que os alunos estavam aprendendo no treinamento. Os dados obtidos nas entrevistas nos domicílios eram ou não anotados, dependendo da receptividade da família. Os assuntos abordados nas reuniões, entretanto, eram sempre registrados.

Durante as apresentações do levantamento, os instrutores procuravam identificar diferentes aspectos: como foi realizado o estudo, qual o número de 
casas visitadas, como foram recebidos, como foi iniciada a conversa, de que forma os moradores colocaram os problemas, como se desenvolveu a conversa, quantas pessoas compareceram à reunião, como esta se processou, como foi a participação das pessoas, como o aluno sentiu o trabalho, que dificuldades e problemas teve, como os encaminhou.

Na tentativa de sistematizar os resultados do levantamento e planejar as demais etapas do trabalho, os instrutores solicitaram aos alunos um relatório individual. Para isto, elaborou-se o roteiro a seguir:

1) Quais as dificuldades que você encontrou para ter uma boa comunicação com as pessoas do bairro?

2) Quais os principais problemas que encontrou nas visitas?

3) Quais os principais problemas levantados nas reuniões e quais as conclusões a que o bairro chegou?

4) No levantamento que você fez, apareceu algum fator novo que tem influência na saúde?

5) O que você acha importante aprender para poder ajudar a resolver os problemas do bairro?

6) Como você se sentiu fazendo esse levantamento?

7) O que você acha que o bairro pensou desse levantamento, da reunião e dos resultados da reunião?

Após a leitura das respostas relativas a cada questão, na dependência da sua natureza, eram retiradas as conclusões, feitos agrupamentos por analogia do assunto, ou desenvolvida uma síntese das respostas.

As respostas à pergunta 5 foram, na realidade, o ponto inicial para seleção do conteúdo a ser aprendido no treinamento, pois já representavam uma síntese dos problemas que os alunos percebiam na comunidade, dos problemas relatados pelos moradores por ocasião das visitas e nas reuniões realizadas nos bairros.

A síntese dos relatórios individuais gerou uma listagem contendo 90 problemas de interesse. A natureza dos assuntos variou muito, desde dor de barriga, dor em volta do umbigo, até problemas de posse de terra, passando por doenças de senhoras, verminose, realização de partos e nefrite, entre outros. Frente a essa diversidade, os alunos foram encarregados de agrupar os problemas que tivessem, em sua opinião, alguma afinidade. Os agrupamentos sugeridos pelos agentes de saúde foram reagrupados, gerando dezoito grandes categorias de problemas, as quais representaram o conteúdo do treinamento que, a partir de então, orientaria o saber, o saber fazer e o saber ser dos agentes de saúde do Vale do Ribeira.

As concepções dos agentes de saúde do Projeto Devale sobre a sua prática são apresentadas na seqüência. Silva (1984) relata que os agentes de saúde 
foram unânimes, durante as entrevistas, em afirmar que o trabalho que desenvolviam era importante para melhorar as condições de saúde nas comunidades em que atuavam.

A forma de expressão dessas conclusões, entretanto, variou bastante, o que pode ser atribuído às diferentes concepções de que eram portadores esses agentes acerca do sentido de seu trabalho.

Foi por causa das dificuldades das pessoas de tomar ônibus para ir à cidade, sabe? É muito longe! As pessoas perdiam o ônibus, chegavam lá não tinha mais horário de consulta, perdiam tempo... Aí resolveram instalar esse postinho aqui. Foi devido a esses problemas.

saiu esse projeto aí, que até botaram cartaz em armazém, venda, que ia ter uma inscrição, sabe, porque o lugar é um pouquinho maior e eles resolveram...

Por que resolveram fazer? Acho que é porque é longe da farmácia, né? Pra chegar na farmácia mais próxima é $8 \mathrm{~km}$. Então não tem recurso nenhum. Eu acho que foi por isso (...) Eu acho que foi um levantamento mesmo do pessoal da saúde pública.

Ah, porque falta de condições, né? Pro pessoal ir à cidade tratar sua saúde... Aí, resolveu fazer o postinho.

Olha, eu... Foi porque ... porque fica muito longe, né? Pra ir daqui pra cidade, né? (...) E a turma aqui, o pessoal não tem assim uma condição, sabe?, financeira, de tar tomando ônibus pra ir pra lá. Como já acontece muito, que vem aqui no postinho, chega aqui, aí eu dou uma guia de exames, qualquer coisa, já não pode ir porque a situação financeira já não tá legal. Então, não dá pra ir, não é? E fica mais perto.

Penso que é pela quantidade de gente que procura os médicos lá em..., e tudo. Então eles viram que a maior necessidade era aqui..., porque não é brinquedo a quantidade de gente que vai. Agora já diminuiu porque muita coisinha, eu estou resolvendo aqui mesmo... mesmo sem o remédio, só com chá caseiro (...) Já não precisa eles pagar ônibus, nem nada, e doente, né?, é duro pegar ônibus doente.

Ao avaliarem a importância do trabalho que realizavam, os agentes de saúde distinguiam duas dimensões: a primeira, referente à satisfação pessoal experimentada, pelo sentimento de sua utilidade, pela consciência de sua contribuição para minorar as dificuldades que a população rural enfrenta; e a segunda, relacionada à própria população e ao significado que o trabalho teria para ela. Em relação à primeira dessas dimensões:

A gente fica contente porque vê que ajuda uma pessoa que necessita, né?

A gente sente-se bem, pois está trabalhando pelos outros, não é? Tem muita gente que precisa, que precisa da gente... 
Eu gosto. Eu gostei do negócio. Eu gosto de tratar crianças.

Eu sempre pensava em ajudar em alguma coisa aqui do bairro... Aí saiu isso e deu certo.

Meu sonho desde criança era esse trabalho.

Ainda em relação à satisfação pessoal, era evidente a consciência dos agentes no que diz respeito às propostas elaboradas para o seu trabalho, mesmo que as observações sobre a prática tenham revelado muitas limitações.

Eu acho que é muito importante ensinar para as pessoas o que eu sei... e o que elas sabem também ensinam, porque tem coisa que a gente não sabe, aprende com os outros.

É a oportunidade que a gente tem de trabalhar com o bairro, aprender com ele, conviver com ele, ver as necessidades dele, sentir mais os problemas do bairro.

Por referência à segunda dimensão, relacionada às necessidades da população, percebia-se primeiramente a idéia de estarem resolvendo ou encaminhando os problemas de saúde:

No início, a gente era inseguro... agora, ninguém fala em médico aqui.

O posto ajuda porque fica mais perto das pessoas.

O trabalho é importante porque a gente lida com a comunidade (...) A gente orienta eles...

A gente aqui explica tudo direitinho... Na farmácia eles só passam remédios, a pessoa nem fica sabendo para que serve.

O estado de saúde da população melhorou muito devido às orientações que a gente pode dar, como no caso das fossas.

$O$ posto ajuda o pessoal, porque eles não precisam gastar dinheiro.

A população reclama muito quando o posto fica fechado, quando a gente sai para fazer visitas.

Ainda não conseguimos chegar ao ideal, porque é difícil, mas já melhorou bastante.

Tornava-se evidente a percepção de que o trabalho, para a população, ultrapassava as dimensões do mero atendimento às necessidades, possibilitando a abertura de um espaço para a discussão e o encaminhamento de outros problemas de saúde, em que as pessoas começavam a compartilhar seus problemas.

$\mathrm{O}$ trabalho do postinho vai além do atendimento. Eles se reúnem aqui, falam o que sentem, o que eles querem..., já têm aquela liberdade...

A gente aqui trabalha com a vontade do bairro.

As pessoas do bairro têm mais liberdade de discutir os seus problemas com os agentes do que em outros lugares.

As pessoas se sentem mais à vontade no atendimento.

A gente ensina para as pessoas tudo o que aprendeu no treinamento. 
Os agentes de saúde também foram unânimes em afirmar que a população estava satisfeita com o funcionamento dos postos. Justificavam essa afirmação pelo fato de a demanda aumentar, a cada dia, e pelos comentários feitos sobre o atendimento recebido. Consideravam que a população confiava, cada vez mais, no trabalho desenvolvido e que vários fatores contribuíam para isto, sendo o mais importante a forma como eram tratados durante o atendimento e, conseqüentemente, a oportunidade de que dispunham para falar dos seus problemas. Para os agentes, a confiança no trabalho que desenvolviam traduziase, ainda, no atendimento às suas prescrições e no comparecimento, quase maciço, aos retornos agendados.

Antes, a população procurava só leite e remédios, não sabiam do atendimento. agora, já se acostumaram.

Eu acredito que a população gosta do trabalho porque cada vez aumenta mais gente, em vez de diminuir.

Eles gostam do jeito porque a gente deixa eles mais à vontade, eles conversam entre si bastante, contam as necessidades, papeiam às vezes com as outras pessoas que vêm junto... (...) $\mathrm{E}$ a gente também vai explicando as perguntas, conversando, dando risada, porque isso daí sempre foi o meu tipo, assim... nessa base.

A primeira coisa que eu fiz depois que eu voltei dos dois meses de treinamento: eu fiz uma visita assim no bairro, explicando o problema que eu tinha estudado... Eu fui de casa em casa explicando tudo $e$ perguntando: qual os problema que você tem aqui?. E marquei uma reunião... então veio um bocado de gente. Então eles achavam que o maior problema que tinha aqui era o esgoto. Porque tem uma vala que atravessa o bairro todo e o esgoto cai dentro dessa vala e estava inundando tudo, e o esgoto estava tomando conta... e tinha que limpar aquilo ali. Então foi feito um mutirão para limpar e abrir aquela vala, $e$ daí por diante eles me viram trabalhando e ficaram sabendo, por causa dessa reunião que eu fiz.

Antes eles perguntavam, no começo, quando ia vir médico, se ia vir médico uma vez por semana... agora não tem mais esse negócio de médico, eles não procuram médico aqui, quando que vem médico, quando não vem...

O treinamento e a conseqüente habilitação proporcionada para o desenvolvimento das atividades foi avaliado, pelos agentes, em termos muito positivos. Entendiam que foi suficiente para resolver a maioria dos problemas, mas não se mostraram capazes de detectar as insuficiências.

$\mathrm{Na}$ análise feita sobre a prática dos agentes, Silva (1984) comparou as freqüências com que eram tomados os diversos tipos de conduta em relação aos motivos de demanda, pela população, e chamou a atenção, sobretudo, para uma baixíssima freqüência com que apareciam os tipos 'prescrição de dietas 
terapêuticas' e 'orientações preventivas', especialmente, se comparadas à freqüência de prescrições de medicamentos industrializados.

Mais notável, entretanto, considerava a autora, era a quase ausência, no padrão de trabalho terapêutico dos agentes, da orientação preventiva. Eram consideradas como condutas pertencentes a este tipo todo o conjunto de orientações para a promoção de saúde (incluídas as discussões sobre as relações entre saúde e todos os tipos de determinantes tão intensa e extensamente presentes no treinamento), todas as medidas de higiene, nucleares no tratamento das doenças infecciosas e parasitárias e todas as medidas de prevenção específica e reabilitação dos agravos à saúde.

Também quando da análise das entrevistas com a população, a autora não evidenciou nenhum padrão de resposta indicativo da eventual captação de proposta integral de trabalho para o agente de saúde, conforme colocada anteriormente, em termos de seus três componentes básicos. A maioria da população entrevistada explicitou um tipo de resposta indicativo de captação da proposta apenas no seu componente de atendimento médico.

Nas conclusões do trabalho, a autora discute as condições que poderiam estar relacionadas às eventuais inadequações verificadas no trabalho desenvolvido pelos agentes em relação à proposta.

Em primeiro lugar, destacou o fato de o Departamento Regional de Saúde da SES não ter incorporado adequadamente o projeto às suas atividades. Ao contrário, pelas informações disponíveis, à Direção do Departamento não interessava o desenvolvimento do projeto, na medida em que o consideravam como um veículo para o desenvolvimento de atividades 'subversivas'. Assim, a idéia inicial de que o Projeto Devale viria a se constituir na própria programação de trabalho do Departamento Regional de Saúde do Vale do Ribeira, até o período estudado (março de 1983), não chegou a se concretizar. O projeto sobreviveu graças ao empenho da equipe de coordenação. Esse fato teria influenciado a forma como se desenvolveram, na prática, algumas atividades de apoio vitais ao projeto.

Como decorrência disto, limites institucionais - entre os quais a sistemática de desenvolvimento de determinadas atividades que não atendiam à forma e ao espírito do projeto - dificultaram a operacionalização através de um processo de orientações conflitantes e, às vezes, até opostas. Entre os limites institucionais, mereceram destaque a forma de supervisão adotada em relação aos postos de saúde e a descontinuação do processo de treinamento, entre outros.

A sistemática de supervisão adotada parecia insuficiente, no aspecto quantitativo, pelo menos, para cumprir plenamente os objetivos - como elevar a qualidade dos serviços prestados e contribuir para o aperfeiçoamento do pessoal, entre outros. O modo como era realizada essa atividade constituía-se em fator 
ainda mais limitante quando se considerava o seu desenvolvimento distante das situações reais de trabalho do agente de saúde e das dificuldades relatadas pela equipe de coordenação do projeto quanto à disponibilidade de recursos materiais. Entre estas, se destacam as relacionadas a veículos e combustivel, além de outras de diferentes naturezas, que forçaram, às vezes, a diminuição das já tão escassas oportunidades de encontro entre agentes e supervisores, para debater sobre o trabalho.

O processo de capacitação dos agentes de saúde, imaginado originalmente como permanente, não foi além da primeira fase. Este fato, aliado às dificuldades operacionais para realizar a supervisão, permitiu que se tirassem conclusões parciais sobre a importância das limitações institucionais na explicação das inadequações detectadas na prática dos agentes de saúde, se referenciado o estudo dessa às propostas que a originaram. Outras dificuldades relatadas também foram consideradas como impondo limites às práticas dos agentes: a ausência de equipamentos para o atendimento a crianças, a gestantes, bem como a irregularidade no fluxo de material de consumo e de medicamentos.

Segundo Silva (1984), por não dispor, muitas vezes, do instrumental básico para desenvolver as atividades para as quais estava sendo treinado e por não encontrar espaço para discutir sobre o trabalho nas condições mais próximas à realidade, o agente de saúde do Devale dificilmente poderia reproduzir as propostas que originaram o projeto e que nortearam o treinamento. Por estes motivos, o esforço que fazia para manter o padrão de trabalho implicava, freqüentemente, o desgaste pessoal.

A análise dos registros das observações referentes ao relacionamento do agente com a clientela referiam, na totalidade dos casos, a existência de um clima de confiabilidade, amizade e descontração, do qual não estava ausente o respeito mútuo. Isto indica, em mais uma dimensão, o cuidado com que o agente procurava desempenhar suas funções.

Ao se analisarem as informações obtidas com as entrevistas com a população, confirmou-se que os postos de saúde eram realmente procurados e valorizados, e os agentes de saúde, bem conceituados pela competência $e$ dedicação com que desenvolviam o seu trabalho. Ainda segundo a autora:

À medida que esses e aquela nunca tiveram acesso regular e ampliado a serviços de saúde, tendem a compartilhar uma mesma expectativa em relação a eles. Pode dar-se que as posições críticas e "pedagógicas" que nortearam o Projeto queimem etapas em relação a essas expectativas, isto é, não seja possível o desenvolvimento de uma cultura que relativize a efetividade dos cuidados 'médicos' sem antes conhecê-los e utilizálos. As entrevistas feitas com os agentes, assim como as feitas com a população, mostram uma identificação entre a melhora das condições de saúde e o conhecimento/utilização dos recursos tecnológicos da 
medicina; se essa identidade pode ser relativizada de uma perspectiva crítica mais global, que parte inclusive da experiência acumulada com o uso em larga escala daqueles recursos, é muito difícil alcançar esse tipo de concepção a partir da carência quase total deles. Isto não invalida, entretanto, de forma alguma, as bases conceituais que presidem o andamento do Projeto, mas pode apenas significar, mais provavelmente, que o tempo de manutenção requerido para que uma avaliação identificasse seu pleno desenvolvimento não tenha sido ainda alcançado. (Silva et al., 1986)

\section{Programa de Agentes Comunitários de Saúde do Estado do Ceará (Pacs-Ceará), 1987}

Para a caracterização do Pacs do Ceará e dos aspectos relacionados ao agente de saúde, utilizaram-se dados e informações obtidos de diferentes fontes, em especial, do Relatório de Projeto de Avaliação coordenado pela Secretaria de Saúde do Estado do Ceará, e desenvolvido, em 1990, por Minayo et al., com o apoio do Fundo das Nações Unidas para a Infância (Unicef). O objetivo do estudo foi identificar os fatos mais importantes gerados no processo de implementação do Programa Agentes de Saúde do Ceará, em especial:

- a potencialidade da proposta com relação à saúde da população;

- as mudanças em alguns indicadores de cobertura de ações de saúde;

- a qualidade das ações executadas pelos agentes de saúde;

- as mudanças nas atitudes e no comportamento das comunidades em relação à proteção à saúde;

- as mudanças na situação de saúde da população-alvo.

Segundo o relatório, a idéia de implantar um programa que incorporasse agentes de saúde já fazia parte do Plano de Governo do Estado, em 1987, no Ceará. A ocorrência de seca de inusitadas proporções e a decisão de abertura de 'frentes de trabalho' para a população de diferentes regiões do Estado em situação mais crítica precipitou o início do Programa. Nestas circunstâncias, o Estado identificou a possibilidade de empregar, a curto prazo, em atividades de promoção da saúde, milhares de moradores de áreas carentes cuja remuneração seria garantida com os recursos dos fundos especiais de emergência, destinados pelo Governo Federal. (Minayo et al., 1990).

Ainda segundo o relatório, entre setembro de 1987 e agosto de 1988, 6.113 pessoas foram contratadas - 95\% mulheres - em 118 municípios do sertão cearense. Após treinamento de duas semanas, elas trabalharam, durante seis a doze meses, desenvolvendo ações básicas de saúde: terapia de reidratação oral, vacinação, orientação para estímulo ao aleitamento materno, entre outras. 


\begin{abstract}
Algumas características das providências tomadas nesta contingência diferenciaram a ação governamental da rotina dos últimos 30 anos. As decisões sobre a seleção do pessoal que receberia salário, que deveria ser o mais pobre, e sobre as obras e atividades para serem executadas, foram tomadas por Grupos de Ação Comunitária - G.A.C.interinstitucionais, especialmente constituídos. Foi contratado um número limitado de pessoas com relação ao passado, chegando-se ao máximo de 235.000 no primeiro trimestre de 1988, à razão de um por família. O pagamento das pessoas cadastradas foi em dinheiro e não em mercadorias. Um salário mínimo foi o valor da remuneração mensal, igual para todos, sensivelmente superior à média local. As atividades executadas, em sua grande maioria, foram em áreas públicas ou de propriedade de pequenos agricultores, evitando-se beneficiar grandes proprietários e dirigindo-se a muitas pequenas obras de interesse comunitário. (Minayo et al., 1990)
\end{abstract}

Foi nesse contexto que aconteceu, no Ceará, a primeira experiência de trabalho em ampla escala com agentes comunitários de saúde, "representando uma tentativa de trabalhar para o desenvolvimento e para o futuro, mesmo em uma crise aguda, na qual o objetivo primordial era a sobrevivência" (Minayo, 1990).

Com o fim do período mais crítico de estiagem, o programa de governo mais amplo foi sendo desativado. O Programa dos Agentes de Saúde, entretanto, teve outro destino. As manifestações das comunidades assistidas e as ponderações dos técnicos levaram o governo do estado a concluir pela manutenção e expansão do programa, agora financiado com recursos do Tesouro do estado (Minayo et al., 1990).

Assim, iniciou-se a do Programa de Agentes de Saúde do Ceará em quarenta e cinco municípios do interior, entre setembro de 1988 e julho de 1989. Por meio de documentos oficiais da SES e de outras fontes, os autores do estudo identificaram os objetivos do programa, as atribuições dos agentes de saúde, assim como outros aspectos de interesse para a caracterização da proposta, aqui reproduzidos.

O objetivo geral do programa seria melhorar a capacidade da comunidade de cuidar da própria saúde. Já os objetivos específicos, de algum modo, expressavam a expectativa em relação à atuação dos agentes de saúde: reduzir o risco de morte ligado ao parto para a mãe e a criança; aumentar a proporção de mães que alimentam os filhos exclusivamente ao seio até quatro meses de vida; reduzir os óbitos causados pela desidratação resultante da diarréia.

O programa previa, em cada um dos municípios envolvidos, atender as necessidades de saúde de toda a população. Outra idéia-chave era "empregar, em áreas entre as mais pobres do Estado, um número relevante de mulheres que assim melhorariam a sua condição social e, possivelmente, estimulariam um posicionamento mais ativo de outras mulheres na sociedade". 
Quanto às ações a serem desenvolvidas pelos agentes de saúde, citavam-se:

- Visitar regularmente (pelo menos uma vez por mês) as famílias da área $e$, com maior intensidade, as que têm crianças menores de 2 anos $e$ gestantes, para: ensinar conhecimentos úteis, incluindo nutricionais, para prevenção e atenção precoce a agravos; fornecer medicamentos antitérmicos; executar curativos de feridas, pesagens periódicas das crianças menores de 2 anos (com acompanhamento na curva de crescimento) e medição do perímetro braquial das gestantes. Haveria o acompanhamento de 50-100 famílias nas áreas rurais e 150-250 nas áreas urbanas por agente.

- Encaminhar às Unidades de Saúde para diagnóstico e terapia, para controles preventivos, particularmente pré-natal, e para prevenção do câncer gineco-obstétrico; encaminhar às Unidades de Saúde para vacinação.

- Promover, organizar ou colaborar com reunióes da comunidade, para discutir e enfrentar assuntos de saúde. Promover, organizar ou colaborar com atividades na própria comunidade, como vacinação ou obras de saneamento. (Minayo et al., 1990).

Os agentes de saúde deveriam trabalhar com outros integrantes da comunidade que, tradicionalmente, já executavam ações de saúde, como as parteiras leigas, os curandeiros locais e outros agentes. Também havia a indicação de que deveriam promover uma atitude ativa e participativa das famílias e da comunidade para a proteção da saúde.

Em termos de seleção, por se exigir residência na comunidade assistida, os agentes não poderiam ser contratados mediante um concurso público convencional. Este aspecto, aliado à necessidade de participação popular, orientou a decisão de que seriam eleitos pela comunidade.

Em relação ao treinamento e supervisão dos agentes de saúde do Ceará, cada grupo de 20 ou 30 agentes vinculava-se a um supervisor de nível superior, em dedicação exclusiva ou, no mínimo, por 20 horas semanais de trabalho. $O$ treinamento incluía uma capacitação inicial de 60 dias sob responsabilidade da supervisão municipal, com ênfase às ações de educação e de promoção da participação comunitária.

Rapidamente, a implementação do programa, no Ceará, atingiu os 45 municípios, selecionando 1.701 agentes de saúde, atendendo a mais de 170 mil famílias e cobrindo uma população de 850 mil habitantes (13,8\% do estado), em julho de 1989. Em setembro de 1990, o programa já funcionava em 84 municípios, com 2.905 agentes que cobriam 290.000 famílias e, aproximadamente, 1.450 .000 habitantes ( $23,5 \%$ do estado; $33 \%$ do interior). Nos municípios em que atuavam, os agentes cobriam uma parcela significativa da população, de 40 a 100\%, com média aproximada de $80 \%$. 
No começo do programa, o vínculo de trabalho dos Agentes foi efetivado através de Bolsa, paga pelo Tesouro estadual.

Os resultados positivos apontados pelo estudo de Minayo et al., em termos de ampliação do acesso das pessoas, da importância e da presença dos agentes nas comunidades, da confiança depositada pela população, da atitude e do compromisso evidenciado no trabalho, bem como na melhoria de determinados indicadores como cobertura vacinal, controle de câncer cérvicouterino, indicadores de qualidade do trabalho e até na redução de doenças que se podem prevenir por imunização, na queda da mortalidade infantil por diarréia foram muito importantes para a continuidade e ampliação do programa, no estado e no país e para a proposição, pelo Ministério da Saúde, do Programa Nacional de Agentes Comunitários de Saúde (Pnacs), em 1991. Também as recomendações acerca das dificuldades e os principais desafios apontados no relatório foram importantes no processo.

\section{Programa Nacional de Agentes Comunitários de Saúde (Pnacs) - Fundação Nacional de Saúde - Ministério da Saúde - 1991}

O Programa Nacional de Agentes Comunitários de Saúde teve seu início em 1991, na região Nordeste do Brasil. Em uma segunda fase, abrangeu parte da região Norte. A idéia inicial era que, em 1992, o Pnacs já estivesse implantado na periferia das grandes capitais e áreas carentes que, ao longo dos anos, vinham apresentando taxas de morbi-mortalidade elevadas.

A justificativa para implantação do programa prendia-se à existência de inúmeras "experiências de atenção primária" em quase todo o Brasil, aos excelentes resultados alcançados, por muitas delas, ao integrar o agente à equipe, não apenas como um elo entre o sistema de saúde e a população mas, principalmente, por sua capacidade de resolver ou evitar parte dos problemas que ocasionavam o congestionamento do sistema de assistência à saúde. Referiam também a significativa contribuição dos ACS, ao oferecer procedimentos simplificados de ações de saúde voltados para práticas de medicina preventiva, para a diminuição da morbi-mortalidade no Brasil e, por conseqüência, para o Sistema Único de Saúde. Também serviram de referência, para o Ministério da Saúde assumir o programa, as avaliações de impactos positivos em diversos locais, entre os quais, o Ceará, o Vale do Ribeira, São Paulo e a contribuição dos agentes no combate à epidemia de cólera.

O propósito do programa, referido através do apoio técnico e financeiro às iniciativas estaduais e municipais na implantação de projetos de agentes comunitários de saúde, seria contribuir para a municipalização e a implantação do Sistema Único de Saúde - hierarquizado, regionalizado e com possibilidade 
de acesso universal. O Pnacs também visava a estender a cobertura dos sistemas públicos de saúde às populações rurais e das periferias urbanas, priorizando a população materno-infantil.

O objetivo geral era expresso em termos de melhoria, através dos agentes comunitários de saúde, da capacidade da população de cuidar de sua saúde, transmitindo-lhe informações e conhecimentos, além de proporcionar a ligação entre a comunidade e os serviços de saúde locais. Os objetivos específicos, por sua vez, incluíam capacitar os agentes para executar trabalhos de primeiro nível de atenção à saúde, garantindo cuidados à população com um grau de resolubilidade compatível com sua função, contribuindo para a extensão da atenção à saúde; garantir o trabalho do agente integrado com a equipe da unidade de saúde a que estivesse vinculado; fortalecer a ligação entre serviços de saúde e comunidade; ampliar o acesso à informação sobre saúde na comunidade; cooperar com a organização comunitária, no trato com os problemas de saúde.

No documento de orientação e treinamento dos agentes de saúde, o Trabalho do Agente Comunitário de Saúde, datado de junho de 1994, identificamse os princípios que geraram a idéia do programa:

- um programa estratégico para contribuir na redução da mortalidade materno-infantil;

- um instrumento para provocar a discussão da organização e ou reorganização dos Sistemas Locais de Saúde (Silos);

- um aglutinador de forças sociais para viabilizar a criação e ou a implementação dos conselhos municipais de Saúde;

- um mecanismo concreto para a interiorização de enfermeiros e, sobretudo,

- uma ponta de lança para mobilização e organização das comunidades.

A área de atuação inicial do Pnacs foi a região Nordeste, onde assumiu como prioridades do trabalho do agente ações de educação em saúde, de mobilização da comunidade e de atenção ao grupo materno-infantil. Na região Norte, no entanto, a implantação ocorreu em caráter emergencial, para fazer frente à epidemia de cólera.

Com base na experiência do Ceará, definiram-se os critérios de seleção dos agentes: ter mais de 18 anos, saber ler e escrever, dispor-se a concluir o 1 으 grau, morar há mais de dois anos na comunidade, dispor de oito horas por dia para o trabalho.

O recrutamento e a seleção dos agentes de saúde eram desenvolvidos em oito fases:

- preparação das coordenaçóes estadual, municipais e articulação com o Conselho Municipal de Saúde; 
- mobilização em que os coordenadores municipais articulavam-se, mobilizavam a comunidade e divulgavam o processo;

- inscrição;

- elaboração da prova;

- aplicação da prova escrita;

- realização de entrevistas (individuais e grupal);

- classificação e publicação dos resultados;

- contratação do agente como bolsista.

Após essas fases, verificava-se o treinamento dos coordenadores regionais e dos instrutores: supervisores municipais, a organização e o treinamento dos agentes.

O coordenador/supervisor deveria, obrigatoriamente, ser enfermeiro, $e$ dispor de, no mínimo, 20 horas semanais para o programa.

Nos documentos do Ministério que normatizam o Pnacs, explicita-se a preocupação da coordenação nacional do programa com a desvinculação de qualquer ingerência político-partidária no processo de recrutamento e seleção dos agentes, condição importe para o bom desempenho do programa.

Em termos de treinamento dos agentes, era previsto que eles teriam uma capacitação que lhes permitisse uma visão abrangente da situação de saúde e habilitação específica para atenção à saúde da comunidade. O processo de aprendizagem não implicava apenas o domínio das técnicas das ações básicas de saúde; fazia-se necessário que o agente compreendesse a comunidade, entendesse seus problemas e a estimulasse a modificar sua relação com a saúde. Assim, o conteúdo da capacitação corresponderia às ações e atividades a desenvolver. O método pedagógico utilizaria a integração ensino/trabalho.

O documento Curso de Formação de Agentes Comunitários de Saúde roteiro de atividades para o coordenador municipal de Saúde - foi elaborado pela coordenação nacional com a colaboração de vários coordenadores estaduais, para os coordenadores municipais. Nele são explicitados os princípios que norteiam o processo de capacitação dos agentes.

Chama a atenção, no conteúdo do programa de treinamento inicial, o capítulo 1: O agente comunitário de saúde - um agente de mudança, em quatro partes.

A primeira parte - Saúde - pretendia que o agente aprendesse a conceituar saúde, com a finalidade de identificar e analisar as condições de saúde da sua comunidade. Para isso ele precisaria "aprender o que é saúde e quais as condições de vida que promovem ou deixam de promover a saúde".

A segunda parte - Saúde e vida comunitária - visava possibilitar que os alunos aprendessem a conceituar vida comunitária, no sentido de estabelecer a relação entre vida comunitária e a promoção da saúde. 
Na terceira parte - As atividades do agente comunitário de saúde - as ações propostas para o agente eram consideradas de reconhecida utilidade e eficácia, para diferentes comunidades. Poderiam, entretanto, ser adaptadas e/ou ampliadas de acordo com a realidade de cada Estado, região ou município, assim como com a situação epidemiológica, a cada momento. Os três eixos principais de atuação dos agentes: educação e saúde, mobilização da comunidade e atenção ao grupo materno-infantil eram assim expresso, nas seguintes ações propostas:

- estimular continuamente a organização comunitária;

- participar da vida da comunidade, principalmenté atravěs das organizações, estimulando a discussão das questões relativàs ă melhoria da qualidade de vida;

- fortalecer os elos de ligação entre a comunidade e os serviços de saúde;

- informar aos demais integrantes da equipe de saúde da disponibilidade, necessidades e dinâmica social da comunidade;

- orientar a comunidade para utilização adequada dos serviços de saúde;

- registrar nascimentos, doenças de notificação compulsória e de vigilância epidemiológica e óbitos;

- cadastrar todas as famílias de sua área de abrangência;

- identificar e registrar todas as gestantes e crianças de 0 a 6 anos de sua área de abrangência, por meio de visitas domiciliares;

- de saúde (acompanhamento a gestantes e nutrizes; incentivo ao aleitamento materno; acompanhamento do crescimento e desenvolvimento da criança; garantia do cumprimento do calendário de vacinação e de outras vacinas que se fizerem necessárias; controle das doenças diarréicas; controle da infecção respiratória aguda; orientação quanto a alternativas alimentares; utilização da medicina popular);

- promoção de ações de saneamento e melhoria do meio ambiente;

- promoção da educação em saúde.

A quarta parte do primeiro capítulo tratava da importância do trabalho do agente comunitário de saúde: $O$ agente comunitário de saúde mobilizando a comunidade; o agente comunitário de saúde conhecendo a comunidade.

Para o treinamento, elaborou-se o Manual do Agente Comunitário de Saúde. Uma preocupação muito evidente da coordenação do programa dizia respeito aos processos de treinamento e educação continuada. Enão era apenas com a questão técnica, mas, principalmente, com o componente político do programa. Para apoiar os instrutores supervisores enfermeiros responsáveis pelos agentes, nos municípios, elaboraram-se muitos manuais e, principalmente, textos de apoio ao trabalho. 
Assim, em O Trabalho do Agente Comunitário de Saúde, editado em 1991, desenvolvem-se detalhadamente conceitos e conselhos sobre como trabalhar com saúde, o que é o agente, como trabalhar com a comunidade e fazer o diagnóstico comunitário. Em 1994, lançou-se uma segunda edição, revista por todos os coordenadores estaduais e assessores do Pacs. Na terceira, já em 2000, identificam-se alterações de conteúdo, defendidas como importantes para atender à evolução do trabalho dos agentes e contemplar a inserção em equipes de saúde da família.

Outra publicação com o mesmo objetivo - o texto de apoio Ações Básicas de Saúde e Desenvolvimento da Criança - trazia, além de ensinamentos sobre o SUS, direitos sociais e cidadania, o papel do agente nesse processo, o detalhamento de conceitos e orientações sobre: desenvolvimento da criança, aleitamento materno, cuidados com o recém-nascido, imunização, controle de doenças diarréicas e de infecções respiratórias agudas.

Nos depoimentos a seguir, podem-se observar concepções sobre o agente comunitário de saúde do Pacs, suas funções e sua identidade:

Ao estimular a formação dos agentes, não se pretende que eles venham a substituir ou preencher o papel de outros profissionais de saúde que lutam no sentido de garantir uma melhor assistência à população. Acredita-se que, por serem pessoas do povo, não só se assemelham nas características e anseios deste povo, como também preenchem lacunas, justamente por conhecerem as necessidades desta população.

Acredito que os agentes são a mola propulsora para a consolidação do Sistema Único de Saúde, a organização das comunidades e a prática regionalizada e hierarquizada de assistência, na estruturação dos distritos sanitários.

Ser agente de saúde é ser povo, é ser comunidade, é viver dia a dia a vida daquela comunidade.

É passar pela rua, pela favela, pelo barraco e sentir que o seu povo necessita do seu trabalho e com o seu trabalho, ela pode ajudar a viver melhor.

É conhecer todas as famílias e sentir em todas elas a sua familia. É sentir que os filhos de todas as mães são um pouco seus filhos.

É ser o elo de ligação entre as necessidades de saúde da população e o que pode ser feito para melhorar suas condições de vida.

É ser a ponte entre a população e os profissionais e serviços de saúde.

O Agente Comunitário é o mensageiro de saúde de sua comunidade. (Dirigente da Fundação Nacional de Saúde)

Ser agente comunitário de saúde é, antes de tudo, ser alguém que se identifica, em todos os sentidos, com a sua própria comunidade, principalmente na cultura, linguagem, costumes; precisa gostar do 
trabalho. Gostar, principalmente, de aprender e repassar as informações, entender que ninguém nasce com destino de morrer ainda criança ou de ser burro. Nós vivemos conforme o ambiente.

É preciso ver que saúde não é só uma coisa de doutor e que favelado tem que cuidar de saúde, sim.

É obrigação dos agentes comunitários de saúde lutar e aglomerar forças em sua comunidade, município, estado e país, em defesa dos serviços públicos de saúde, pensar na recuperação e democratização desses serviços, entendendo que é o serviço público que atende à população pobre; é preciso torná-lo de boa qualidade. Precisamos lutar por outros fatores que são determinantes para a saúde como: trabalho, salário justo, moradia, saneamento básico, terra para trabalhar e participação nas esferas de decisão dos serviços públicos. (Agente comunitária de saúde, Recife)

A principal estratégia de preparação de agentes comunitários de saúde teria como base a mobilização da comunidade, que deveria respaldar o desenvolvimento e o fortalecimento do trabalho cotidiano. A informação e a discussão do Pnacs com a comunidade eram colocadas como os principais meios para isso, sendo que a sensibilização das comunidades deveria permear todas as etapas de implantação do programa.

A interação e o relacionamento dos agentes com a estrutura profissional da enfermagem era uma dos temas que mais levantavam controvérsias. O Fórum de Entidades Nacionais da Enfermagem - composto pela Associação Brasileira de Enfermagem, Conselho Federal de Enfermagem, Federação Nacional dos Enfermeiros e União Nacional dos Auxiliares e Técnicos de Enfermagem integrava, desde 1991, a comissão consultiva à coordenação nacional do Pnacs com a finalidade de elaborar um anteprojeto e, em articulação com a coordenação nacional, participar do acompanhamento, avaliação e supervisão da implantação do projeto. A preocupação das entidades nacionais da enfermagem de que a incorporação de agentes comunitários de saúde para o desenvolvimento de ações básicas de saúde, algumas delas identificadas com as da enfermagem, pudessem significar um aumento do contingente de trabalhadores sem qualificação, como os atendentes, levou-as a assumir uma posição de questionamento e até de enfrentamento ao Ministério da Saúde.

Se inúmeras foram as oportunidades de negociação, tanto nos estados quanto no âmbito federal, alguns foram os entendimentos. Em um compromisso assumido pela Fundação Nacional de Saúde, do Ministério da Saúde, se garantia às entidades da enfermagem que, após a capacitação inicial dos agentes em ações básicas de saúde, mobilização e educação sanitária, haveria continuidade do processo de formação, com a finalidade de habilitá-los em auxiliar de enfermagem comunitário. Deveria também viabilizar-se, mediante entendimentos 
com o sistema educacional, a continuidade da escolaridade para nível de 1 은 grau, paralelamente à formação profissionalizante - atendendo ao que estabelece o Conselho Federal de Educação e a Lei no 7.498 de 25 de junho de 1986, que regulamenta o exercício da enfermagem no país. Em agosto de 1991, a presidente da Fundação Nacional de Saúde e os Dirigentes das Entidades Nacionais de Enfermagem (Conselho Federal de Enfermagem, Associação Brasileira de Enfermagem e Federação Nacional dos Enfermeiros) assinaram, em Brasilia, um termo de compromisso, inclusive de responsabilidade sobre o financiamento da formação.

Em 1992, o Pnacs perdeu o termo nacional, passando a chamar-se Pacs. Assinaram-se convênios entre a FNS/MS e as secretarias estaduais de Saúde para repasse de recursos para custeio do programa e o pagamento, sob a forma de bolsa, no valor de um salário mínimo mensal aos agentes.

Em 1993, o PACS já abrangia 13 estados das regiões Norte e Nordeste, com 29 mil agentes comunitários de saúde atuando em 761 municípios. A estratégia definida previa a ampliação, em 1994, para novos municípios das mesmas regiões, bem como para o Centro-Oeste.

Em novembro de 1994, as secretarias estaduais de saúde coordenaram uma avaliação do programa em oito estados, realizada por universidades e apoiada pelo Unicef. Na ocasião, o Programa já se encontrava implantado em 987 municípios do país, de 17 estados das regióes Norte, Nordeste e CentroOeste, e incluía um total de 33.488 agentes. A idéia da coordenação nacional era que um olhar externo, especialmente das universidades, pudesse identificar os pontos positivos e as necessidades de ajustes e reorientações.

No documento Avaliação Qualitativa do Pacs, descreve-se o estudo desenvolvido entre setembro e novembro de 1994. Na metodologia adotada, incluíram-se entrevistas com os usuários. Entre os vários aspectos positivos apresentados, citam-se o reconhecimento dos usuários pelo trabalho do agente comunitário de saúde em importantes reflexos na cobertura vacinal, na terapia de reidratação oral; no início precoce dos exames pré-natais, no conhecimento dos agentes pelo nome, quando comparados os dados obtidos para população coberta e não coberta pelo programa. Ao lado das evidências positivas, o relatório da pesquisa sugere necessidade de aprimorar o processo de supervisão dos agentes e da sua formação profissional. Além desses aspectos, o relatório aponta para uma articulação insuficiente do agente com outros profissionais e com os serviços de saúde, e do programa com o sistema de saúde dos municípios onde está implantado. 


\section{Programa de Saúde da Família (PSF) - FNS/MS -1994}

O Programa de Saúde da Família foi idealizado em 1993 e oficializado em 1994, mas a sua expansão nacional efetiva ocorre a partir de 1995 (Viana \& Dal Poz,1998). Desde o início, a concepção do programa era de fazê-lo um instrumento de reorganização do SUS e da municipalização, estando definido que sua implantação deveria privilegiar áreas de maior risco social. A partir de 1995, são definidos e institucionalizados mecanismos e patamares de financiamento e muitos municípios passam a se interessar pelo programa, particularmente, aqueles com uma estrutura de atenção básica ainda pouco desenvolvida.

Em final de 1993, foi divulgado, pelo Ministério da Saúde, o primeiro documento sobre o PSF, resultado de uma reunião com vários secretários estaduais e municipais de Saúde, professores universitários, especialistas e técnicos.

O PSF é apresentado, nessa primeira versão, como um modelo de assistência à saúde que visa a desenvolver ações de promoção e proteção à saúde do indivíduo, da família e da comunidade, utilizando o trabalho de equipes de saúde responsáveis pelo atendimento na unidade local de saúde e na comunidade, no nível de atenção primária.

Entre os pontos principais da proposta, destacam-se:

- cada equipe básica do PSF seria responsável pela cobertura de uma área geográfica onde habitassem de 800 a 1.000 familias. Este critério poderia ser alterado, em função das condições de acesso e da densidade demográfica do município;

- as equipes do PSF seriam compostas por um médico, um enfermeiro, um auxiliar de enfermagem e quatro a seis agentes de saúde. A estrutura das equipes poderia ser modificada de acordo com a realidade local. Caberia ao Sistemas Locais de Saúde (Silos) garantir a supervisão e a atualização dos profissionais;

- a equipe do PSF deveria residir na comunidade onde iria atuar e trabalhar em regime de dedicação exclusiva. Posteriormente, tendo em vista as dificuldades, esse critério de residência ficou como obrigatório apenas para o agente comunitário de saúde;

- cada pessoa da família receberia atenção integral da equipe do PSF, independentemente da idade e do estado de saúde. As equipes seriam responsáveis pela execução de ações para prevenção e controle da incidência de doenças;

- o PSF seria a porta de entrada ao sistema de saúde em todas as localidades onde estivesse implantado; 
- o controle da qualidade de serviços prestados pelo PSF e a avaliação do desempenho profissional da equipe de saúde seriam exercidos por grupos de supervisão, pelos Conselhos de Saúde e pelas comunidades atendidas;

- os objetivos apresentados:

- melhorar o estado de saúde da população através de um modelo de assistência, voltado à família e à comunidade, que inclua desde a proteção e a promoção da saúde até a identificação precoce e o tratamento das doenças.

- divulgar o conceito de saúde como qualidade de vida e direito do cidadão;

- promover a família como o núcleo básico da abordagem no atendimento à saúde da população, em um enfoque comunitário;

- prestar atendimento básico de saúde, de forma integral, a cada membro da familia, identificando as condições de risco para a saúde do indivíduo;

- proporcionar atenção integral, oportuna e contínua à população, no domicilio, em ambulatórios e hospitais;

- agendar o atendimento à população, com base nas normas dos programas de saúde existentes, sem descartar a possibilidade de atendimentos eventuais e domiciliares;

- humanizar o atendimento e estabelecer um bom nível de relacionamento com a comunidade;

- organizar o acesso ao sistema de saúde;

- ampliar a cobertura e melhorar a qualidade do atendimento no sistema de saúde;

- promover a supervisão e a atualização profissional para garantir boa qualidade e eficiência no atendimento;

- levar ao conhecimento da população as causas que provocam as doenças e os resultados alcançados na sua prevenção e no seu tratamento;

- incentivar a participação da população no controle do sistema de saúde.

A população-alvo do PSF seria, prioritariamente, residente nas áreas delimitadas no Mapa da Fome do Instituto de Pesquisa Econômica Aplicada (Ipea), de acordo com as características geográficas e a distribuição da população, em cada município. A escolha das áreas onde seria implantado o Programa deveria, também, observar os seguintes critérios:

- realização de mapeamento das áreas do município indicadas para a implantação do Programa;

- interesse da comunidade em participar do PSF; 
- necessidades de saúde locais; demanda por serviços;

- oferta atual de serviços;

- existência de apoio para o diagnóstico e tratamento de doenças, consultas especializadas e hospitais que assegurem o atendimento adequado e a eficiência do Programa;

- disposição da administração municipal em adotar o modelo de assistência à saúde proposto pelo PSF e em participar do seu financiamento.

Quanto à participação social, as equipes não deveriam atuar isoladamente, mas buscar, sempre que possivel, a parceria com os diversos segmentos da sociedade. Para garantir a participação ativa da comunidade, deveriam desenvolver-se ações de educação e promoção da saúde, com a difusão permanente de informações. Assim, seria possível aumentar a participação das organizações populares no planejamento, execução e avaliação do programa, bem como contribuir para o controle social das ações e serviços de saúde.

As instituições privadas e as entidades sem fins lucrativos também deveriam ser estimuladas a colaborar com o Programa, fornecendo material para as unidades de saúde e moradia para os profissionais do PSF.

O treinamento e a supervisão dos profissionais eram aspectos já referidos, com ênfase. A formação básica dos profissionais de saúde integrados ao PSF deveria ser direcionada para esse modelo de atenção, o que exigiria qualificação técnica e identificação com os objetivos do trabalho.

A identificação de um dos principais desafios para realização do programa - a capacitação das equipes - levou o ministério a incentivar a organização de pólos regionais de capacitação, um movimento de articulação com as universidades. Houve, também, grande investimento, em especial nas articulações e na produção de material didático para a capacitação dos agentes comunitários de saúde.

Documentos do Ministério da Saúde de 1997 e 1998 reforçam o entendimento do PSF como uma estratégia para reorganização do modelo de atenção básica à saúde, no país:

O objetivo do PSF é a reorganização da prática assistencial em novas bases e critérios, em substituição ao modelo tradicional de assistência, orientado para a cura de doenças no hospital. A atenção está centrada na família, entendida e percebida a partir do seu ambiente físico e social, o que vem possibilitando às equipes de Saúde da Família uma compreensão ampliada do processo saúde/doença e da necessidade de intervenções que vão além de práticas curativas. (Brasil. Ministério da Saúde, 1998)

Quanto aos princípios que orientavam a atuação das unidades básicas sob o enfoque de saúde da família, eram referidos: 
- caráter substitutivo: substituição das práticas convencionais de assistência por um novo processo de trabalho, cujo eixo está centrado na vigilância à saúde;

- integralidade e hierarquização: estar inserida no primeiro nível de ações e serviços do sistema local de saúde e vinculado à rede de serviços, de forma a garantir a referência e contra-referência sempre que forem requeridas ações mais especializadas;

- territorialização e adscrição de clientela: trabalhar com território de abrangência definida e população cadastrada, recomendando-se que cada equipe seja responsável, no máximo, por 4.500 pessoas;

- equipe multiprofissional: cada equipe de saúde da família deverá ser composta, minimamente, por um médico generalista ou médico de família, um enfermeiro, um auxiliar de enfermagem e de quatro a seis agentes comunitários de saúde.

No documento Saúde da Familia: uma estratégia para a reorientação do modelo assistencial, de 1997, são reforçados pontos centrais do programa. O primeiro é o estabelecimento de vínculos, bem como a criação de laços de compromisso e de co-responsabilidade entre os profissionais de saúde e a população. A perspectiva, segundo essa fonte, faria com que a familia passasse a ser o objeto precípuo de atenção, entendida a partir do ambiente onde vive.

Mais que uma delimitação geográfica, é nesse espaço que se constróem as relaçóes intra e extrafamiliares e onde se desenvolve a luta pela melhoria das condições de vida - permitindo, ainda uma compreensão ampliada do processo saúde/doença e, portanto, da necessidade de intervenções de maior impacto e significação social. As ações sobre esse espaço representam desafios a um olhar técnico e político mais ousado, que rompa os muros das unidades de saúde e enraíze-se para o meio onde as pessoas vivem, trabalham e se relacionam. (Brasil. Ministério da Saúde, 1997)

O segundo ponto é o fato de que o PSF caracteriza-se como uma estratégia que possibilita a integração e promove a organização das atividades em um território definido, com o propósito de propiciar o enfrentamento e resolução dos problemas identificados.

Ainda nessa publicação, o Ministério nega a identificação do PSF como um sistema de saúde pobre para os pobres, com utilização de baixa tecnologia.

Tal assertiva não procede, pois o Programa deve ser entendido como modelo substitutivo da rede básica tradicional - de cobertura universal, porém assumindo o desafio do princípio de eqüidade - e reconhecido como uma prática que requer alta complexidade tecnológica nos campos do conhecimento e do desenvolvimento de habilidades e de mudanças de atitudes. (Brasil. Ministério da Saúde, 1997) 
A análise dos objetivos colocados para o PSF, nos documentos de 1997 e 1998, aponta para diferenças em relação à primeira proposição, de 1993:

- Contribuir para a reorientação do modelo assistencial a partir da atenção básica, em conformidade com os princípios do Sistema Único de Saúde, imprimindo uma nova dinâmica de atuação nas unidades básicas de saúde, com definição de responsabilidades entre os serviços de saúde e a população.

- Prestar, na unidade de saúde e no domicílio, assistência integral, contínua, com resolubilidade e boa qualidade às necessidades de saúde da população adscrita.

- Intervir sobre os fatores de risco aos quais a população está exposta.

- Eleger a família e o seu espaço social como núcleo básico de abordagem no atendimento à saúde.

- Humanizar as práticas de saúde através do estabelecimento de um vínculo entre os profissionais de saúde e a população.

- Propiciar o estabelecimento de parcerias através do desenvolvimento de ações intersetoriais.

- Contribuir para a democratização do conhecimento do processo saúdel doença, da organização dos serviços e da produção social da saúde.

- Fazer com que a saúde seja reconhecida como um direito de cidadania e, portanto, expressão da qualidade de vida.

- Estimular a organização da comunidade para o efetivo exercício do controle social. (Brasil. Ministério da Saúde, 1997)

Nessa estratégia, assim aparecia a previsão de atribuições do agente comunitário de saúde:

O ACS desenvolverá suas ações nos domicílios de sua área de responsabilidade e junto à unidade para programação e supervisão de suas atividades. São suas atribuições básicas:

- realizar mapeamento de sua área de atuação;

- cadastrar e atualizar as famílias de sua área;

- identificar indivíduos e famílias expostos a situações de risco;

- realizar, através de visita domiciliar, acompanhamento mensal de todas as famílias sob sua responsabilidade;

- coletar dados para análise da situação das famílias acompanhadas;

- desenvolver ações básicas de saúde nas áreas de atenção à criança, à mulher, ao adolescente, ao trabalhador e ao idoso, com ênfase na promoção da saúde e prevenção de doenças;

- promover educação em saúde e mobilização comunitária, visando uma melhor qualidade de vida mediante açóes de saneamento $e$ melhorias do meio ambiente;

- incentivar a formação de conselhos locais de saúde; 
- orientar as famílias para a utilização adequada dos serviços de saúde;

- informar os demais membros da equipe de saúde acerca da dinâmica social da comunidade, suas disponibilidades e necessidades;

- participação no processo de programação e planejamento local das ações relativas ao território de abrangência da unidade de Saúde da Família, com vistas à superação dos problemas identificados. (Brasil. Ministério da Saúde, 1997)

Em dezembro de 1997, uma Portaria Ministerial estabelece a prioridade, no Plano de Metas do Ministério da Saúde, para os Programas de Agentes Comunitários de Saúde e de Saúde da Família, estimulando a sua expansão em todo o território nacional. Na Portaria, reconhecem-se, ainda, o Pacs e o PSF como importantes estratégias "para contribuir no aprimoramento e na consolidação do Sistema Único de Saúde, a partir da reorientação da assistência ambulatorial e domiciliar". No mesmo instrumento, são aprovadas normas e diretrizes para o Pacs e o PSF, entre as quais diretrizes operacionais para o trabalho dos agentes comunitários de saúde, nos dois programas.

Em um documento datado de 1999, o Ministério da Saúde conceitua atenção básica como um conjunto de ações, de caráter individual ou coletivo, situadas no primeiro nível de atenção dos sistemas de saúde, voltadas para a promoção da saúde, a prevenção dos agravos, o tratamento e a reabilitação. A ampliação do conceito é considerada necessária para avançar na direção de um sistema de saúde centrado na qualidade de vida das pessoas e de seu meio ambiente. A organização da Atenção Básica é relacionada à Lei n. 8.080, e aos princípios do SUS: saúde como direito; integralidade da assistência; universalidade; eqüidade; resolutividade; intersetorialidade; humanização do atendimento; participação popular.

A vinculação institucional dos agentes é um tema que desde a primeira proposição do Pnacs já aparecia como um dos principais desafios a enfrentar na implantação do Programa. Na época da publicação do último documento referido, a forma de contratação dos agentes, a sua vinculação, continuava sendo um dos pontos de maior preocupação, tendo em vista a necessidade de mantê-los na sua comunidade e, ao mesmo tempo, de proporcionar-lhes as garantias da legislação do trabalho. Muitos têm sido os movimentos do Ministério da Saúde, mas essa situação, até a conclusão deste livro, permanecia ainda como uma das pendências.

Em dezembro de 1998, após cinco anos de funcionamento, o PSF estava implantado em 24 estados (ausente apenas em Roraima, Amapá e Distrito Federal), 1.219 municípios, com 3.119 equipes. Avaliação desenvolvida pelo Ministério da Saúde, em 1999, demonstrou que 83\% dos municípios implantaram o PSF entre 1997 e 1998, sendo que apenas o Ceará e Santa Catarina tinham 
um número maior de municípios com implantação anterior a 1997. Era também - Ceará, desta vez com Minas Gerais, que apresentava o maior número de municípios com o programa em atividade (Brasil. Ministério da Saúde, 1999).

No Estado de São Paulo, segundo dados da Secretaria Estadual de Saúde, eram referidos, até o final de 1999, 111 municípios com o PSF e 98 municípios com o Pacs, abrangendo um total de 2725 agentes comunitários de saúde e 237 equipes de saúde da família.

O número acima referido, entretanto, não incluía São Paulo (capital), pois o PSF em funcionamento não estava vinculado ao Município, mas ao Estado, em decorrência de opção política municipal por outro sistema, o PAS. O Programa de Saúde da Família, no município de São Paulo, iniciado em 1996, recebeu a denominação de Projeto Qualis - Qualidade Integral em Saúde - e, embora calcado no modelo dos PSF, apresentou, desde o início, particularidades, por referência à proposta nuclear, tanto em relação à forma de gestão, operacionalizada através de parcerias do Estado com organizações sociais, quanto à organização das atividades assistenciais, ao se inserir em um contexto diferenciado, uma metrópole como São Paulo.

Uma tentativa de síntese das propostas apresentadas possibilitará a identificação de pontos importantes, aspectos nucleares da conformação da identidade do agente de saúde, tema central deste livro. Os aspectos discutidos nesta síntese serão retomados tendo em vista a discussão da identidade e a identificação de analogias e especificidades entre os sujeitos de propostas anteriores e os agentes comunitários de saúde do Qualis. Assim, estarão sendo identificadas "tipologias de agente comunitário" que existiram, em determinados momentos e contextos históricos.

$\mathrm{Na}$ realidade, quando se analisam, em uma primeira aproximação, as propostas colocadas, identificam-se, de um lado, características básicas comuns $e$, de outro, expressões de uma grande variabilidade, nos acordos construídos, na prática, em torno do agente de saúde nas suas diversas concepções e denominaçóes, acordos esses que se refletem em especificidades importantes do perfil ocupacional. Portanto, embora bastante parecidos, esse agentes, poder-seia dizer, serão sempre um tanto quanto diferentes, de acordo com os contextos e momentos históricos em que se inserem.

Quanto ao contexto histórico em que emergiram e à justificativa e objetivos apresentados, a Sesp e a F.Sesp, que a substituiu, teve sua origem em contexto de esforço de guerra, ligada, desse modo, a questóes econômicas de manter ou assegurar a higidez da força de trabalho: trabalhadores e seus familiares. Com o passar do tempo, a F.Sesp passou a responsabilizar-se pela prestação de serviços de saúde, aí incluídos os de saneamento básico a populações definidas, nos municípios onde estava instalada ou se instalou por solicitação de governos estaduais. 
Já o Piass foi proposto como expressão de política pública, em contexto de regime de exceção, no bojo de medidas que visavam à manutenção da estrutura de poder dominante. As justificativas e os objetivos expressavam a preocupação com as populações marginais que viviam sob condições de extrema pobreza e o propósito de diminuir a marginalidade social e produtiva, em um primeiro momento, nos estados da região Nordeste.

Quanto ao Projeto Devale, viabilizado após decisão política de expansão nacional do Piass, caracterizava-se, evidentemente, como iniciativa de extensão de cobertura e de interiorização de ações de assistência à saúde e saneamento. Apesar de ter as mesmas raízes, o Piass Nordeste e o do Vale do Ribeira diferenciaram-se, logo de início, em alguns pontos fundamentais, como se pôde observar, em especial na expectativa de atribuições e de impacto das ações dos agentes de saúde. O Piass era coordenado por um grupo de médicos e enfermeiros sanitaristas que destacavam, na atuação do agente, a promoção dos direitos sociais e da cidadania. O Departamento Regional de Saúde do Vale do Ribeira, ao qual o programa estava oficialmente ligado, na época, em 1981, não o assumiu como política do Estado e, pelo contrário, muitos foram os problemas que a equipe de Coordenação teve para implantar e desenvolver o projeto.

O Pacs do Ceará, em suas origens, é proposto em um contexto de emergência social e econômica, de calamidade pública. A ênfase, no primeiro momento, era o programa "frentes de trabalho", como gerador de emprego $e$ renda. Já na segunda fase de implantação do Programa, foi deslocada para o agente de saúde a viabilização de uma política de extensão de cobertura e de interiorização das ações de saúde, que muito se assemelhava às desenvolvidas pelos auxiliares de saúde do Piass do Nordeste.

Inspirado na experiência do Ceará, do Devale e de muitos municípios brasileiros que implantaram propostas similares a partir da eleição direta para prefeitos, assumindo algumas diretrizes básicas do programa do Ceará, o Pnacs (posteriormente Pacs) aparece em um contexto de redemocratização do país, do primeiro Presidente da República eleito após o regime militar. No Plano de Ação do Governo Federal para o Ministério da Saúde, estava prevista, entre outras metas, a contratação de 100 mil agentes comunitários de saúde. Um diálogo permanente entre a coordenação nacional e as coordenações estaduais do programa, a definição de mecanismos de financiamento, os resultados obtidos nas regiões onde estava sendo instalado, garantiram os movimentos, a articulação e as ações técnicas necessários à consolidação da proposta. Mais uma vez, o sujeito da estratégia era o agente de saúde, selecionado na área onde iria trabalhar.

O PSF, por sua vez, embora concebido posteriormente e lançado também como proposta oficial do Ministério da Saúde, não representava uma substituição do Pacs. Surgiu para responder a necessidades e articulações de muitos locais e, 
até por esta razão, teve uma expansão importante. Convive-se, hoje, no país, com os dois programas que foram propostos e justificados para a reversão, em regiões específicas, de condições adversas de saúde e de acesso a serviços e, como conseqüência, de seus reflexos, indicadores desfavoráveis de morbi-mortalidade.

Quanto ao sujeito de realização das propostas, a F.Sesp não tinha o agente de saúde, mas o visitador sanitário, auxiliar que, ao lado do 'atendimento de enfermagem' a crianças e gestantes sadias e a outros grupos prioritários e atividades de 'pós-consulta', na unidade, desenvolvia atividades em visitas domiciliares e na comunidade. O seu perfil, pode-se dizer, era diferente do requerido para o agente de saúde.

Em primeiro lugar, ele não era recrutado na população. As pessoas do município que se interessavam e possuíam o equivalente ao atual $2^{\circ}$ grau completo inscreviam-se para a seleção que constava de prova e entrevista. Era o que se poderia chamar de agente institucional assumido. Não havia dúvidas quanto a isso e nem expectativa que ele desenvolvesse qualquer mobilização popular, mas um trabalho de discussão com a população sobre como encaminhar e prevenir problemas de saúde. As suas ações incluíam a educação para a saúde, orientações, acompanhamento de crianças, gestantes e adultos, ações de prevenção e monitoramento de doenças, controle de parteiras leigas. Ele, como toda a unidade de saúde, tinha metas a cumprir - de vacinas, de gestantes, de crianças, de tuberculosos a serem detectados e atendidos. A sua referência era o enfermeiro, tanto para o treinamento, quanto para a supervisão, e ele efetivamente realizava ações e procedimentos relacionados à prática de enfermagem.

Ao contrário dos outros programas aqui descritos, a ênfase do trabalho da F.Sesp, para o cumprimento de sua missão, não se colocava no agente, mas no conjunto dos profissionais organizados em uma unidade de saúde, a qual tinha uma programação com metas a cumprir.

Já a viabilização da política de extensão de cobertura e de interiorização das ações de saúde e saneamento, no caso do Piass, assentava-se na atuação de um sujeito, recrutado na própria comunidade onde iria atuar, o auxiliar de saúde. O trabalho deste indivíduo, desenvolvido a partir de uma unidade básica de pequena estrutura, os minipostos rurais, deveria atingir toda a população da localidade. Para isso, contaria com uma participação da população - pelo que se deduz, de natureza bastante utilitarista.

A estrutura de suas atividades envolvia uma grande variedade de ações, desde a prevenção de doenças transmissíveis, a educação para a saúde, ações de saneamento básico, até o atendimento das doenças mais freqüentes, na localidade. $\mathrm{O}$ atendimento implicava a realização de atividades e de procedimentos caracterizados como da área de enfermagem e até, em muitos casos, incluía o diagnóstico e o tratamento dessas patologias, conforme padronização institucional. 
A principal diferença, conforme já se observou, entre o Piass Devale e os seus congêneres do Nordeste, referia-se ao rol de atividades definido para o sujeito encarregado de viabilização do Programa e, por conseqüência, à expectativa do impacto de sua atuação. Pela análise do Projeto Devale, conseguese identificar, no conjunto de ações propostas para o sujeito - denominado agente de saúde -, dois componentes principais. O primeiro se poderia considerar mais estritamente técnico, relacionado ao atendimento aos indivíduos e famílias, a intervenção para promoção da saúde ou para o monitoramento de grupos ou problemas específicos. Ao lado deste, outro que parecia ter uma importância fundamental na concepção do programa era o componente que se identifica como político, não apenas de solidariedade à população, de discutir saúde no contexto geral de vida, mas no sentido de organização da comunidade, de transformação dessas condições. O agente deveria ser um elemento de transformação social e não apenas de reorientação da concepção e da realização do modelo de atenção à saúde. Essa é uma dimensão importante e diferenciada da proposta do Projeto Devale em relação aos demais. Um reflexo muito importante disso é evidenciado na concepção do treinamento inicial, na metodologia, na definição e no desenvolvimento do conteúdo.

Há fortes evidências de que, com raras exceções, os agentes de saúde do Vale do Ribeira, embora tenham assumido, com o tempo, um perfil, uma identidade mais institucional, mantiveram bastante intensa a solidariedade com a população, grupo de onde se originaram e pelo qual foram eleitos.

Com relação ao Pacs do Ceará, identifica-se uma diferença entre os dois momentos - o de emergência, em função da seca, e o do Programa de Agentes de Saúde, propriamente dito - em vários aspectos, desde o rol de ações, o treinamento e a supervisão, até no relacionamento com a população.

Já o Pacs Nacional, desde o início, guardou muitas analogias, mas também muitas especificidades em relação a seu principal inspirador, o programa do Ceará. Em primeiro lugar, a negociação, durante todo o processo, com as entidades da enfermagem. Como conseqüência, em um primeiro momento, o compromisso de que, com o apoio técnico e financeiro do Ministério, os agentes seriam formados em auxiliar de enfermagem comunitário.

Uma segunda característica, também importante para a conformação da identidade profissional do agente: a coordenação Nacional do Pacs exigia, nas negociações com os estados e os municípios, que o supervisor/instrutor do trabalhador fosse um enfermeiro e não um profissional de nível superior, como se defendia no Ceará. Essa condição ocasionou uma verdadeira 'caça a enfermeiros', por parte dos municípios e estados que se dispuseram a implantar - Programa. As repercussões da exigência para a inserção e valorização profissional do enfermeiro são muito evidentes, inclusive na intensificação da 
demanda para os cursos de enfermagem, em todo o território nacional. A coordenação do Pacs ainda hoje exige a presença de um enfermeiro para treinamento e supervisão dos agentes. A iniciativa, entretanto, de formá-los em auxiliar de enfermagem comunitário foi reavaliada, até em função das realidades locais e não mais colocada no cenário de possibilidades.

Na recuperação histórica desse sujeito de viabilização de políticas de saúde cabem, ainda, duas considerações, de ordem bem geral, acerca das atribuições do agente de saúde, da expectativa de impacto de suas ações e da sua relação com a comunidade de onde se originou.

Quanto ao primeiro aspecto, ressalta-se a idéia de que o trabalho do agente, na maioria das propostas, ultrapassava as dimensões de um mero atendimento às necessidades, ou seja, tratava-se do trabalho e de algo mais do que o trabalho; da saúde e do que transcendia a concepção mais restrita de saúde. Porém, a identidade de profissão apresentava-se como muito tênue. Estas idéias serão desenvolvidas ao longo deste estudo.

Abordam-se, aqui, um pouco a sua relação do agente com a instituição e com a comunidade, interações fundamentais para a conformação de sua identidade. Os primeiros agentes de saúde do Ceará eram, talvez mais - ou exclusivamente - da comunidade. Eles vinham das frentes de trabalho, eram pessoas quaisquer, não eram nem selecionadas, não lhes era exigido perfil. Eram pessoas que vinham para trabalhar, não eram nem agentes da comunidade, nem faziam parte dela; não a representavam. Mas essa não era uma preocupação, porque eles eram muito mais representantes mesmo sem saber, de uma maneira que é quase do senso comum. Quando se consideram os agentes de outras propostas, parece evidente, com o tempo, uma predominância da referência à instituição e não tanto à comunidade de onde se originaram.

Em síntese, ainda que se identifiquem aspectos comuns entre todos os programas aqui referidos, cada contexto e os seus atores introduziram, certamente, diferenças importantes em cada um dele. Consideram-se a negociação local, o contexto, os agentes, os demais sujeitos e a sua relação, como as condições mais importantes para as características de concepção e de viabilização dessas propostas de política, em cada um dos locais e momentos históricos.

\section{O Programa de Saúde da Família no Municíito de São PAulo - Qualis/PSF}

\section{ANTECEDENTES E CONTEXTO}

A Constituição brasileira de 1998 contemplou a saúde como um direito social, cuja garantia é responsabilidade de cada um e de todos e, em especial, 
do Estado, assegurando duas condições básicas: políticas públicas - econômicas e sociais para a redução de riscos - $e$ acesso a todos os brasileiros a serviços $e$ ações de saúde.

Assim, a Carta Magna de 1988 e a legislação que a sucedeu abrem novas perspectivas para reforço e legitimação/legalização de novos modelos de organização da assistência que assegurem os princípios e as diretrizes do Sistema Único de Saúde, entre os quais, a universalidade, a integralidade e a eqüidade.

Conforme já se mencionou, no começo dos anos 90, o Ministério da Saúde assumiu a implantação, em nível nacional, do Pacs. A evolução dos Pacs e seus resultados, os processos nos locais onde foram implantados, o processo de acompanhamento fizeram com que, em alguns locais, fossem introduzidas transformações. Esse processo evoluiu para a institucionalização, em meados da década de 90, do PSF. Nesse ínterim, implantaram-se outros Pacs e PSFs em vários municípios, com graus variados de êxito na implantação e nos resultados observados.

Aparecem alguns relatos mais otimistas, outros mais moderados, todos, entretanto, ressaltando os resultados positivos e as perspectivas do modelo, benefícios e possibilidades enquanto estratégia para cumprimento dos ditames constitucionais e para melhoria da saúde e da qualidade de vida.

Quando se consideram as diferentes propostas, consegue-se identificar que, na sua trajetória de implantação, nas diferentes regiões, em especial nos anos 90, a justificativa dos PSFs tem seguido quatro eixos principais de argumentação, eixos esses perseguidos em paralelo e cuja sustentação, em termos de lógica, referem-se a:

- ampliação do acesso;

- racionalidade técnica e econômica, enfocando tanto a racionalização das atividades para o sistema e para o paciente, como os aspectos econômicos, de otimização de recursos, inclusive de custos para o paciente: fazer o melhor, de maneira menos dispendiosa, possibilitando a ampliação do acesso às ações de saúde a um número maior de pessoas;

- humanização do atendimento, em várias expressões e significados, entre os quais, a recuperação do vínculo na relação profissional de saúde/ paciente, familia, comunidade;

- integralidade do atendimento, em duas principais perspectivas, complementares e articuladas. Em uma, trabalha-se a abordagem integrada $e$ integral do indivíduo, em sua dimensão de cidadão (biopsicossocial), de cidadão na família e da família na comunidade, o que implica, além de uma postura diferenciada de cada um dos agentes do trabalho, uma atuação articulada de equipe multiprofissional e de equipamentos e níveis de atenção. Já a outra tem como base um conceito 
do processo saúde-doença. Implica uma abordagem e a articulação multi-setorial para o êxito nas ações de promoção, proteção $e$ recuperação da saúde dos indivíduos e da comunidade.

Nessas perspectivas, aparece, como referência privilegiada para a realização da proposta, a constituição/atuação de equipes de saúde da família integradas por um médico, um enfermeiro, um auxiliar de enfermagem e quatro agentes comunitários de saúde, com responsabilidade por oitocentos a mil familias residentes em uma área geográfica determinada (Brasil. Ministério da Saúde, 1997).

Uma função muito especial está reservada ao médico de família e ao agente comunitário de saúde para a viabilização do modelo e, por conseqüência, do resultado das intervenções, ao estar centrado no desenvolvimento de cuidados permanentes e preventivos e não na doença e no hospital (Jatene, 1998).

Quando se consideram as zonas urbanas, a inserção desse tipo de programa assume várias especificidades e características outras, ampliando as necessidades de análise e de abordagem, na medida em que se inserem em sistemas de saúde mais complexos, já estruturados, com uma história, uma lógica complexa, inclusive na relação público/privado, com motivações e interesses variados.

Na cidade de São Paulo, onde as iniciativas anteriores desembarcaram de forma muito tímida, e não sistematizadas, o novo modelo de PSF foi implantado, em abril de 1996, com a denominação de Projeto Qualidade Integral em Saúde (Qualis) - em três áreas da capital.

A Região Metropolitana da Grande São Paulo, na década de 70, foi objeto do Plano Metropolitano de Saúde (PMS), proposta da Secretaria de Estado da Saúde, com financiamento do Banco Mundial, com o envolvimento das prefeituras dos municípios da região. Especificamente para a zona Leste da capital, foi prevista a instalação de uma rede hierarquizada de serviços de saúde, com a construção de unidades básicas e de hospitais de referência.

Nessa mesma região, no final dos anos 80 , implantou-se, também por iniciativa do governo estadual, o Programa de Consultórios de Médico de Família, mediante co-gestão entre a Secretaria de Estado de Saúde e a Casa de Saúde Santa Marcelina, entidade filantrópica religiosa já instalada na zona Leste, com um importante hospital. Para o novo programa, a proposta de atuação seguia o modelo cubano, com o médico de familia trabalhando com um auxiliar de enfermagem e residindo na área de abrangência. Foram abertos, inicialmente, 17 consultórios de família, na região. A experiência, entretanto, por diferentes motivos, não se ampliou. Em 1995, eram apenas sete os consultórios de médicos de família, na área.

Considera-se que essa experiência teve, certamente, influência na implantação e no desenvolvimento do Qualis, na região Leste da capital. Os consultórios remanescentes do Programa de Médicos de Família, as unidades 
básicas, foram aproveitados e a população do local já trazia uma experiência de participação, o que deu um tom, certamente, específico ao novo programa assumido pela Casa de Saúde Santa Marcelina. Além disso, antigos médicos de família ocuparam, de imediato, funções de formuladores, coordenadores e viabilizadores da nova estratégia.

Em novembro de 1995, após um período de negociações, o Governo do Estado de São Paulo assumia, em articulação com o Ministério da Saúde e em parceria com uma entidade filantrópica, a Casa de Saúde Santa Marcelina, a implantação do PSF, no município de São Paulo, com a denominação de Projeto Qualis - Qualis I. Apresentam-se, a seguir, as justificativas que faziam parte da proposta inicial.

- Existência de unidades básicas de saúde pertencentes à rede da SES-SP nas quais não se havia efetivado a fixação de profissionais de saúde, dentro da política tradicional de recursos humanos, por vários anos.

- Existência de equipes treinadas e com experiência, disponíveis para contratação, possibilitando a viabilização do funcionamento das UBS em curto prazo.

- Expectativa das comunidades das áreas referidas no que concerne ao atendimento de suas necessidades básicas de saúde, com manifestações expressas através de vários abaixo-assinados e solicitações de reuniões com a SES-SP.

- Viabilidade e interesse de utilização das UBS como campo avançado para aperfeiçoamento técnico profissional de residentes de clínica médica, pediátrica, ginecologia, medicina geral e comunitária, internato médico e profissionais de enfermagem sob supervisão do Centro de Estudos e Escola de Enfermagem da Casa de Saúde Santa Marcelina.

- O fato de a Casa de Saúde Santa Marcelina ser uma instituição filantrópica reconhecida pelos serviços prestados à comunidade da região.

- Alta demanda primária e secundária atendida nos ambulatórios e prontosocorro da Casa de Saúde Santa Marcelina.

- Experiência prévia entre a SES-SP com a Casa de Saúde Santa Marcelina, parceiros no Projeto Médico de Familia, implantado em 1989.

- Interesse de reorganização e aumento de qualidade na prestação de serviços de saúde dos núcleos regionais III e V, da SES.

Como objetivo geral do projeto, constava a reorganização do modelo assistencial, tendo por base a promoção, proteção, diagnóstico precoce, tratamento e recuperação da saúde, em conformidade com os princípios e diretrizes do Sistema Único de Saúde. Já os objetivos específicos eram: 
- promover o conceito de saúde como um direito de cidadania e como qualidade de vida;

- promover a família como núcleo básico da abordagem no atendimento à saúde da população em um enfoque comunitário;

- prevenir as doenças e identificar fatores de risco aos quais a população está exposta;

- fornecer atenção integral, oportuna, contínua e de boa qualidade nas áreas básicas de saúde à população adstrita, seja no nível domiciliar, ambulatorial ou hospitalar;

- atender a população adstrita, preferencialmente através de agendamento, obedecendo às normas dos programas de saúde existentes, preservando, a possibilidade de atendimentos eventuais e domiciliares;

- buscar a humanização do atendimento e, através do inter-relacionamento da equipe com a comunidade, proporcionar maior satisfação do usuário;

- racionalizar o acesso e o fluxo do sistema de saúde (do nível de atenção primária até os de maior complexidade);

- estimular a extensão da cobertura e a melhoria da qualidade do atendimento no sistema de saúde;

- garantir, aos profissionais do PSF, supervisão, educação continuada, cursos de capacitação e treinamentos para se aprimorar;

- divulgar, junto à população envolvida, os dados produzidos pelos serviços, bem como informações sobre os fatores determinantes de doenças;

- incentivar a organização da comunidade para o efetivo exercício do controle social.

Depois de pouco mais de um ano de funcionamento, com uma cobertura de apenas $1 \%$ da população do município, considerou-se que o Qualis apresentava resultados extremamente positivos e uma aceitação de mais de $90 \%$ da população residente na área de abrangência. Ao lado destes resultados favoráveis, identificaram-se também alguns problemas que, segundo a coordenação estadual, não deveriam ser reproduzidos quando da expansão do modelo para outras áreas da capital. Entre estes, citavam-se a descontinuidade da área abrangida e as insuficiências detectadas no funcionamento da retaguarda especializada, o que afetava os mecanismos de referência e contrareferência e a plena eficácia do modelo.

Foi com base nesses resultados e no conhecimento desses problemas que surgiu a proposta de expandir o Projeto Qualis/PSF para os subdistritos de Vila Nova Cachoeirinha, Parque São Lucas e Sapopemba. Nestas localidades, existiam duas unidades de saúde do Estado reformadas ou construídas, além de outras oito em funcionamento precário. 
Assim, em outubro de 1997, ampliou-se o Projeto Qualis com a parceria com a Fundação Zerbini - Qualis II, com a instalação de unidades básicas de saúde e de dois ambulatórios de especialidades, nas regiões Norte e Sudeste da capital. A idéia era a articulação também com os hospitais mais próximos, o que asseguraria a retaguarda para aqueles casos que tivessem indicação de internação. Também os exames complementares - tanto laboratoriais como de imagens - estariam assegurados. Nem a Fundação Zerbini, nem os coordenadores do Qualis II viveram o Programa de Médico de Família, o que deveria expressarse em especificidades quando da comparação da proposta e da realização dos dois projetos de Qualis. Essa abordagem, entretanto, embora os dados disponíveis permitissem o seu aprofundamento, por fugir aos objetivos do trabalho, não foi considerada quando da análise dos dados empíricos.

Até o final de 1998, foram implantadas, no Qualis Santa Marcelina, 40 equipes de saúde da família, atuando em 12 unidades e com um ambulatório de especialidades, tendo sido cadastradas 25.628 famílias, ou 102.783 pessoas. No Qualis II, para o mesmo período, foram implantadas 35 equipes, sendo 22 na zona Norte e 13 na zona Sudeste, com dois ambulatórios de especialidades, atendimento em saúde bucal e saúde mental, uma casa de parto em Sapopemba, tendo sido cadastradas 32.129 familias, ou 121.768 pessoas.

Eram assim colocadas as atribuições do agente comunitário de saúde do Projeto Qualis/PSF:

- atuar de acordo com as diretrizes e normas do PSF;

- integrar a equipe de saúde da família, participando de todas as atividades de diagnóstico, planejamento e avaliação das ações individuais $e$ coletivas, visando à proteção e à promoção da saúde da comunidade;

- desenvolver ações educativas junto à população, priorizando os grupos de maior vulnerabilidade, como gestantes, crianças menores de 5 anos, idosos, portadores de doenças crônicas, visando à conquista da saúde;

- estimular, junto com os demais integrantes da equipe, a participação popular, no sentido de que a comunidade amplie a sua consciência sobre os problemas de saúde e seus determinantes, visando a sua superação;

- identificar situações de risco individual e coletivo, e desenvolver ações de vigilância com vistas à redução da morbi-mortalidade e ao controle das doenças;

- participar ativamente das ações de educação continuada e dos cursos de capacitação profissional visando ao desenvolvimento do seu papel profissional e como agente de mudanças; 
- acolher o usuário de forma humanizada, ouvindo seus problemas e solicitações, dando as respostas adequadas de acordo com sua competência;

- cadastrar as famílias de sua área de abrangência e atualizar periodicamente os dados sobre nascimentos, óbitos e doenças;

- registrar corretamente as ações desenvolvidas e as informações colhidas na comunidade;

- encaminhar doentes à unidade de saúde e realizar acompanhamento específico de acordo com a orientação da sua equipe de saúde;

- realizar visitas domiciliares sistematicamente às famílias cadastradas;

- notificar as doenças e participar das ações de vigilância epidemiológica e sanitária;

- estimular ações de saneamento e melhoria do meio ambiente na sua área de atuação;

- desenvolver ações básicas de saúde pertinentes à sua função tais como: incentivo ao aleitamento materno, acompanhamento de crescimento $e$ desenvolvimento, verificação das carteiras de vacinação, orientação de gestantes e nutrizes, uso de sais de reidratação oral;

- atuar de forma integrada a outras instituições relacionadas à saúde da comunidade;

- não divulgar informações recebidas durante as visitas domiciliares a quaisquer pessoas que não pertençam à equipe de saúde;

- notificar imediatamente a equipe mudanças de endereço de família da área;

- executar toda e qualquer outra atividade incluída no campo de ação de sua função;

- notificar imediatamente a equipe, caso venha a transferir seu domicílio para outra área.

Em síntese, o Projeto Qualis emerge em um contexto geográfico e político específico, uma grande metrópole, São Paulo, caracterizada tanto pela concentração de recursos materiais e humanos na área de saúde como pela desigualdade social e de acesso a serviços. A cidade de São Paulo vivia, na ocasião, uma determinada conjuntura política em que a prefeitura implantava um modelo de assistência à saúde dissociado do SUS. O convênio para o Qualis foi feito, então, mediante convênio entre a Secretaria de Estado da Saúde e uma instituição filantrópica, privilegiando a zona Leste, que já havia abrigado uma proposta alternativa de atenção básica à saúde, o Projeto Médico de Família, bem como tinha sido palco de uma série de movimentos populares, que se 
desdobraram na instalação de equipamentos sociais e no desenvolvimento de relações entre Estado e comunidade com base na participação popular.

Abre-se, assim, um importante mercado de trabalho para indivíduos residentes nas áreas de abrangência do projeto. Até o fim de 1998, contrataramse 300 agentes comunitários de saúde. Eles foram incluídos em equipes de trabalho que contavam com um médico, um enfermeiro e um ou dois auxiliares de enfermagem, com proposta de atuação para a unidade básica, o domicílio e a comunidade.

A equipe deveria fazer reuniões de supervisão, em que se discutissem casos e situações. Seu trabalho seria orientado pela vigilância à saúde: fazer as visitas mensais às famílias, desenvolver ações para a promoção da saúde e a prevenção de doenças, principalmente ações educativas e controlar os grupos de maior risco. O preenchimento dos dados diários de produção e a contabilização mensal conformariam o seu ritmo de trabalho e o conteúdo básico das visitas.

Nessas condições, no contato relativamente mais íntimo com os demais profissionais e com o trabalho assistencial da unidade, em comparação com experiências do tipo dos agentes do Piass, foi sendo conformada a sua identidade. A sua relação com a população deveria estar pautada pela busca da humanização do atendimento; ao mesmo tempo, o agente comunitário de saúde teria como função incentivar a organização da comunidade com vistas ao controle social. 